\title{
Influence of steel reinforcement on the performance of elastomeric bearings
}

\author{
Konstantinos N Kalfas ${ }^{1}$, Stergios A Mitoulis ${ }^{2}$, Dimitrios Konstantinidis ${ }^{3}$
}

\begin{abstract}
Seismic isolation is an effective measure for mitigating the earthquake hazard on important structures such as hospitals, bridges, and nuclear power plants. Seismically isolated structures should remain essentially elastic for the design earthquake, experiencing minimal or no damage. Steel-reinforced elastomeric bearings are seismic isolation devices that are used extensively for the protection of bridges. Because isolators are critical elements of an isolated bridge, they should experience limited, if any, damage during earthquake shaking that exceeds the design level. Damage associated with yielding of the reinforcing steel shims in seismic isolation elastomeric bearings has received limited attention in the literature. In this context, this paper investigates the effect of the steel reinforcement characteristics on the behaviour of rubber bearings under combined axial load, shear displacement, and rotation. The potential of damage in the steel shims under design shear strains is investigated by utilising a damage factor, $\Omega$, with emphasis being placed on various steel shim thickness values. The investigation is carried out using advanced finite element analysis simulations in ABAQUS/CAE. The research showed that local stresses are developed within the steel shims that exceed the yielding limit of the steel reinforcements. These stresses cause permanent deflections and local damage that alters the properties of the isolators.
\end{abstract}

KEYWORDS: elastomeric bearing; steel shims; shim thickness; plasticity ratio; damage factor; vulnerability; residual deflections; rotation; non-linearity

\footnotetext{
${ }^{1}$ Ph.D. Candidate, SM ASCE, Department of Civil and Environmental Engineering, Southern Methodist University, Dallas, TX 75205; E-mail: kkalfas@ @mu.edu

(corresponding author)

${ }^{2}$ Associate Professor, Faculty of Engineering \& Physical Sciences, University of Surrey, Guildford, Surrey, GU2 7XH, UK; E-mail: s.mitoulis@ surrey.ac.uk, www.infrastructuresilience.com

${ }^{3}$ Assistant Professor, Department of Civil and Environmental Engineering, University of California, Berkeley, CA 94720; E-mail: konstantinidis@ berkeley.edu
} 


\section{INTRODUCTION}

Steel-reinforced elastomeric bearings are composite devices comprised of alternate layers of elastomer and steel.

Research on the development and behaviour of elastomeric bearings is at the forefront of earthquake engineering

(Stanton et al. 2007; Aria and Akbari 2013; Naeim and Kelly 1999). These devices are used for the seismic isolation of bridges, buildings, and various critical facilities such as nuclear power plants (Kalfas et al. 2017b; Tubaldi et al. 2016; Mitoulis 2015; Kumar and Whittaker 2018). The bearings can accommodate different deformations caused by earthquakes and static or quasi-static movements (Mitoulis 2015; Kumar and Whittaker 2018), whilst significantly reducing the loads on critical structural components, such as bridge piers and foundations. The ability of bearings to accommodate horizontal deformations is attributed to their small shear stiffness in comparison to the stiffness of other structural components (e.g. piers). In contrast, the stiffness of the bearings under compressive loads is relatively high, in order for them to support the weight of the structure without excessive vertical deflections (Naeim and Kelly 1999). This high compressive stiffness is achieved by the presence of the steel shims, which constrain the global lateral bulging of the rubber. This constraining effect in the rubber generates tensile stresses within the shims that, if they become large enough, could cause failure through yielding or fracture of the elastomer. Furthermore, when the top support of the bearing is laterally displaced relative to the bottom support, bending moments develop in the bearing. Based on previous research by the authors (Kelly and Konstantinidis 2009; 2011) these moments affect the in-plane stresses in the shims. The failure of the steel shims in an elastomeric bearing under combined loading and the overall behaviour of the isolator after such a failure has occurred, are not well understood.

The research about the thickness of the multiple steel shims and the response of the isolators following their yielding is scarce. Kelly and Takhirov (2001) investigated the influence of the steel shim thickness on the performance of bearings, but the residual rotations and axial deflections which cause yielding of the steel shims were not accounted for. Kelly and Konstantinidis (2009) analytically investigated the behaviour of the steel shims in elastomeric bearings. Closed-form solutions were developed for the stresses in the shims when the bearings are subjected to pure compression and pure rotation. The study considered both the case of low-shape-factor bearings, for which incompressibility of the elastomer may be assumed, and the case of high-shape-factor seismic isolation bearings, for which the bulk compressibility of the elastomer is considered. Kelly and Konstantinidis (2009) 
pressure that causes full yielding of the shims, for the case when the elastomer is assumed incompressible, is a conservative estimate of the corresponding pressure for the more general case of large-shape-factor bearings. The work of Kelly and Konstantinidis $(2009 ; 2011)$ focused on pure compression or pure bending assuming linear elastic rubber and infinitesimal strain theory, while the behaviour of the steel shims under combined loading considering nonlinearity in both the materials and geometry has not, to the best of the authors' knowledge, been investigated. Hence, the influence of the steel shims yielding on the behaviour of elastomeric bearings when subjected to the large demands that arise during earthquake loading has not been studied comprehensively.

Current design guidelines provide guidance regarding the modelling of the bearings, limitations and prescriptions concerning the acceptable design limit states and describe the behaviour of the bearings (EN 1337-3 2005; EN 1998-2 2005; AASHTO 2014). However, the existing design guidelines regarding the behaviour of the steelreinforced elastomeric bearings following the yielding of the steel shims when they are imposed to cyclic loading, are limited. EN 1337-3 (2005) provides the minimum thickness of the shims, but there is no guidance on the response of the elastomeric bearings following the yielding of the shims; EN 1337-3 (2005) does not cover the cases where the plates might yield under shearing. EN 1998-2 (2005) provides details regarding the total thickness of the elastomer of the steel-reinforced elastomeric bearings, but no guidance is given regarding the thickness of the shims. Both EN 1998-2 (2005) and AASHTO (2014) allow small, finite support rotation, i.e. rotation of the upper anchor plate, or relative rotation. The design approaches of the standards worldwide, regarding the response of the bearings after the reinforcement yields and the influence of the upper support rotation on the overall behaviour of the bearings, are matters that require further investigation.

Reconnaissance surveys on bridges after major earthquakes in South America and Asia (Kwon and Jeong 2013; Takahashi 2012) have noted instances where bridge bearings suffered from rotations of the upper anchor plates and from excessive tensile stresses even when their global response was shearing and axial compression. Quite a few Japanese bridges designed by post-1990 codes, despite the fact that the incorporated elastomeric bearings and unseating prevention devices had been enhanced prior to the occurrence of the 2011 Tohoku earthquake (Kawashima and Matsuzaki 2012; Kawashima et al. 2011), experienced extensive damages during the earthquake (Xiang and Li 2017). More recently, Panetsos (2016) conducted a thorough inspection of bridge bearings in Greece. Quite a few steel-reinforced elastomeric bearings seemed to suffer from delamination of the elastomer from the steel shims, and from residual rotations of the samples which caused permanent yielding to the steel shims and severe degradation of the elastomer behaviour, highlighting a well-documented but not researched issue with regard to vulnerabilities of steel-laminated elastomeric bearings. 
Many studies have focused on the response of steel-reinforced elastomeric bearings subjected to pure shear or pure axial compressive loads. For example, Stanton et al. (2007) examined a large number of possible deformations that steel-reinforced elastomeric bearings experience, and which may result in local damages, such as cavitation of the rubber under pure compression and pure rotation. Van Engelen and Kelly (2014) proposed simplified closed-form solutions for the design of the properties of elastomeric bearings, by accounting for the bulk modulus and by considering incompressible and compressible behaviour of the elastomer. In addition, Van Engelen et al. (2016; 2017b) proposed code formulas for steel- and fiber-reinforced elastomeric bearings under pure compression and pure rotation, taking into account the effects of elastomer bulk compressibility and reinforcement extensibility. Later, Van Engelen et al. (2017a) quantified the maximum shear strain demands that arise in elastomeric bearings under rotation. Various studies have also addressed the behaviour of steel-reinforced elastomeric bearings under combined axial loads and shear displacements (Kalfas et al. 2017a; 2017b; Maureira et al. 2017; Nagarajaiah and Ferrell 1999; Weisman and Warn 2012). Furthermore, recent studies (Rastgoo Moghadam and Konstantinidis, 2017; Forcellini et al., 2017; Han and Warn, 2015; Ravari et al., 2012; Crowder and Becker, 2017) examined the effect of rotation of the top and bottom of elastomeric bearings, as well as the influence of the combination of the axial loads and shear displacements, on the behaviour of the isolators.

The objectives of this study are to better understand the influence of the steel shim thickness on the behaviour of elastomeric bearings, to characterize the behaviour of the bearings after yielding of the steel shims, to investigate the possibility of residual curvatures and axial deformations within the steel shims, and to investigate the influence of the upper anchor plate rotation on the behaviour of the isolators. These objectives are addressed by identifying the development of local stresses within the steel shims and the permanent curvature/axial deformation of the steel shims when the bearings are subjected to combined actions that include axial loads (corresponding to vertical stress ranging from $2 \mathrm{MPa}$ tension to $10 \mathrm{MPa}$ compression), cyclic shear displacements (corresponding to shear strains of up to $150 \%$ ), and cyclic rotations applied to the upper anchor plate. Four steel-reinforced elastomeric isolators with various geometric configurations were modelled and analyzed using the FEA software ABAQUS/ CAE Ver. 6.13 (Dassault Systèmes 2014a; 2014b). The hyperelastic Ogden material (1972) was used to model the elastomer in all the analyses, while the Faridmehr et al. (2014) model was used to account for the inelastic behaviour of steel. 


\subsection{Geometry of bearings}

119

The geometry of the four steel-reinforced elastomeric bearings considered in this study is described in detail in

Table 1 in conjunction with Fig. 1 . The symbol used for these bearings, i.e. $B_{i}$, denotes the bearing with steel shims of thickness i (in mm). The upper and lower anchor plates, the elastomeric layers, and the steel shims were circular with a diameter of $400 \mathrm{~mm}$. The diameter of the model bearings was obtained from a real bridge design used in the Egnatia Motorway in Northern Greece (Mitoulis 2015). These steel-laminated bearing sizes are typical in a large number of isolated bridges especially with precast-prestressed beams in earthquake-prone areas. Those steel-reinforced elastomeric bearings consisted of a total of six layers of elastomer, five steel shims, and two anchor plates. The bearings had a total elastomer thickness of $66 \mathrm{~mm}$, i.e. six elastomeric layers of $11 \mathrm{~mm}$ each. The thicknesses of the upper and lower anchor plates were $25 \mathrm{~mm}$. The total height of the steel shims of the bearings studied here was $5 \mathrm{~mm}, 10 \mathrm{~mm}, 20 \mathrm{~mm}$, and $30 \mathrm{~mm}$. These models are referred hereinafter as Bearing 1 , 2, 4, 6 and denoted as $\mathrm{B}_{1}, \mathrm{~B}_{2}, \mathrm{~B}_{4}$ and $\mathrm{B}_{6}$ i.e. five steel shims for each bearing having a thickness of $1 \mathrm{~mm}$ for $\mathrm{B}_{1}$, $2 \mathrm{~mm}$ for $\mathrm{B}_{2}, 4 \mathrm{~mm}$ for $\mathrm{B}_{4}$ and $6 \mathrm{~mm}$ for $\mathrm{B}_{6}$. EN 1337-3 (2005) requires a minimum thickness of $5 \mathrm{~mm}, 2 \mathrm{~mm}$, and $18 \mathrm{~mm}$ for each elastomeric layer, steel shim, and anchor plate, respectively. Therefore, the thickness of the layers of $B_{2}, B_{4}$ and $B_{6}$ are within the limits proposed by EN 1337-3 (2005). The steel shim thickness of $B_{1}$ is below the 2-mm limit of EN 1337-3 (2005). Very thin shims may pose constructability challenges due to bending and warping during vulcanization, resulting in a distorted bearing. Additionally, thin shims may buckle or yield under low loading demands. Nonetheless, the model with 1-mm-thick steel shims is used in this study because it allows a lower-bound perspective. It is worth mentioning that the minimum thickness is a result of safety against yielding, whilst the maximum thickness should be limited to reduce the total thickness, cost, and weight of the bearing.

Table 1. Geometry of the bearings: $\mathrm{B}_{1}, \mathrm{~B}_{2}, \mathrm{~B}_{4}$, and $\mathrm{B}_{6}$.

\begin{tabular}{cccc}
\hline \hline & bearing(s) & symbol (unit) & value \\
\hline diameter of the bearings & $\mathrm{B}_{1}$ to $\mathrm{B}_{6}$ & $D(\mathrm{~mm})$ & 400 \\
\hline area of the elastomeric layer & $\mathrm{B}_{1}$ to $\mathrm{B}_{6}$ & $A_{b}\left(\mathrm{~mm}^{2}\right)$ & 125664 \\
\hline & $\mathrm{B}_{1}$ & $T_{1}(\mathrm{~mm})$ & 121 \\
total height of the bearings & $\mathrm{B}_{2}$ & $T_{2}(\mathrm{~mm})$ & 126 \\
& $\mathrm{~B}_{4}$ & $T_{4}(\mathrm{~mm})$ & 136 \\
& $\mathrm{~B}_{6}$ & $T_{6}(\mathrm{~mm})$ & 146 \\
\hline
\end{tabular}




\begin{tabular}{cccc}
\hline \hline & bearing(s) & symbol (unit) & value \\
\hline elastomer layer thickness & $\mathrm{B}_{1}$ to $\mathrm{B}_{6}$ & $t_{\mathrm{r}}(\mathrm{mm})$ & 11 \\
\hline number of elastomeric layers & $\mathrm{B}_{1}, \mathrm{~B}_{2}, \mathrm{~B}_{4}$, & & \\
& $\mathrm{B}_{6}$ & $n_{\mathrm{r}}(-)$ & 6 \\
\hline total elastomer thickness & $\mathrm{B}_{1}$ to $\mathrm{B}_{6}$ & $T_{\mathrm{r}}(\mathrm{mm})$ & 66 \\
\hline \multirow{5}{*}{ single steel shim thickness } & $\mathrm{B}_{1}$ & $t_{\mathrm{s} 1}(\mathrm{~mm})$ & 1 \\
& $\mathrm{~B}_{2}$ & $t_{\mathrm{s} 2}(\mathrm{~mm})$ & 2 \\
& $\mathrm{~B}_{4}$ & $t_{\mathrm{s} 4}(\mathrm{~mm})$ & 4 \\
\hline number of steel shims & $\mathrm{B}_{6}$ & $t_{\mathrm{s} 6}(\mathrm{~mm})$ & 6 \\
\hline & $\mathrm{B}_{\mathrm{i}}$ & $n_{\mathrm{s}}(-)$ & 5 \\
\hline total steel shim thickness & $\mathrm{B}_{1}$ & $T_{\mathrm{s} 1}(\mathrm{~mm})$ & 5 \\
& $\mathrm{~B}_{2}$ & $T_{\mathrm{s} 2}(\mathrm{~mm})$ & 10 \\
& $\mathrm{~B}_{4}$ & $T_{\mathrm{s} 4}(\mathrm{~mm})$ & 20 \\
\hline single anchor plate thickness & $\mathrm{B}_{1}$ to $\mathrm{B}_{6}$ & $t_{\mathrm{AP}}(\mathrm{mm})$ & 30 \\
\hline number of anchor plates & $\mathrm{B}_{1}$ to $\mathrm{B}_{6}$ & $n_{\mathrm{AP}}(-)$ & 25 \\
\hline total anchor plate thickness & $\mathrm{B}_{1}$ to $\mathrm{B}_{6}$ & $T_{\mathrm{AP}}(\mathrm{mm})$ & 2 \\
\hline \hline
\end{tabular}
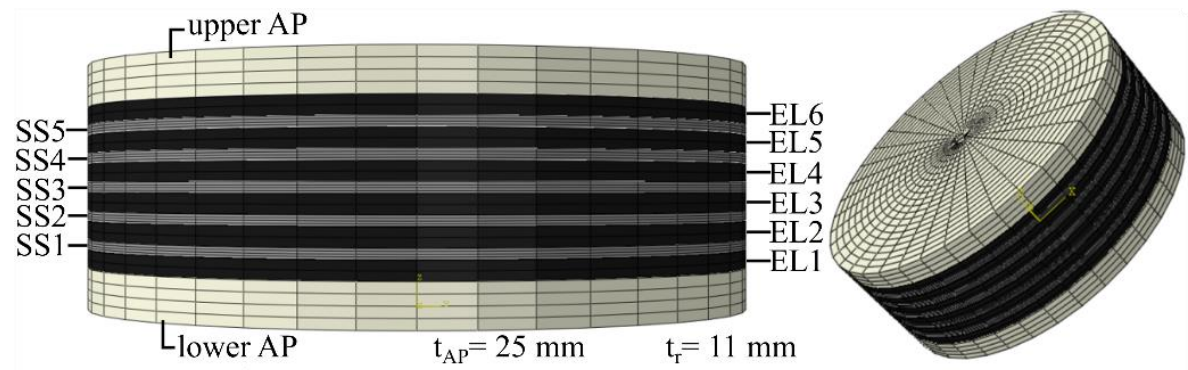

$\mathrm{t}_{\mathrm{si}}=1,2,4$ and $6 \mathrm{~mm}$

Fig. 1. The geometry and the three-dimensional model of the steel-reinforced elastomeric bearings as built-in ABAQUS/CAE (SS $S_{\mathrm{i}}$ : Steel Shim i, EL $\mathrm{i}_{\mathrm{i}}$ : Elastomeric Layer i, AP: Anchor Plate, $\mathrm{t}_{\mathrm{si}}$ : thickness of the steel shim i, $t_{\mathrm{AP}}$ : thickness of the anchor plate, $\mathrm{t}_{\mathrm{r}}$ : thickness of the rubber layer).

\subsection{Mechanical properties of the elastomer and the steel reinforcements}

The material used for modelling the elastomer layers of the reference steel-reinforced elastomeric bearings was the Ogden material (Ogden 1972). The constitutive laws of the Ogden hyperelastic material were found to be quite accurate representing natural rubber, a highly non-linear material; thus, a large number of published researches used this model before (Kalfas et al. 2017b; Titirla et al. 2017; Ohsaki et al. 2015). The stress-strain relationship of the Ogden model is derived from a strain energy density function (Eq. (1)). A hysteresis material model (Dassault Systèmes 2014a) is used in conjunction with the Ogden hyperelastic material model to more accurately represent the behaviour of the elastomer. Moreover, the behaviour of the elastomer, including the dissipation capacity, i.e. damping, can be described accurately by a hyperelastic material, which is highly deformable and 
quasi-incompressible. As such, in order for the shear strains, the rotations and the variable axial loads to be imposed to the isolators, the mechanical properties of the Ogden hyperelastic material were employed for the analyses. Table 2 shows the values of the parameters concerning the strain energy density function, the calculation of the shear modulus and the Poisson's ratio. These values have already been described in Kalfas et al. (2017a; 2017b), and the strain-density function of the Ogden hyperelastic material is developed in Eq. (1) below:

$$
\mathrm{U}=\sum_{n=1}^{2} \frac{\mu_{n}}{\alpha_{n}}\left(\bar{\lambda}_{1}^{\alpha_{n}}+\bar{\lambda}_{2}^{\alpha_{n}}+\bar{\lambda}_{3}^{\alpha_{n}}-3\right)+4.5 B\left(J^{\beta}-1\right)^{2}
$$

where $\mu_{1}, \alpha_{1}, \mu_{2}, \alpha_{2}$ and $\beta$ are the hyperelastic parameters obtained from Bradley et al. (2001), $J$ is the elastic volume ratio and $\overline{\lambda_{1}}, \overline{\lambda_{2}}$ and $\overline{\lambda_{3}}$ are the deviatoric stretches.

The values of the hysteretic parameters of the Ogden model were selected as those suggested in the ABAQUS/CAE manual (Dassault Systèmes 2014a), based on the work of Bergström and Boyce (1998). The parameter that influences the damping ratio of the isolator is the stress scaling factor, which was taken as $\mathrm{S}_{\mathrm{SF}}=$ 1.6. The values of the additional hysteretic parameters for the Ogden model in this study were adopted from Bergström and Boyce (1998): Creep Strain Exponent C= -1; Effective Stress Exponent m= 4; and Creep Parameter $\mathrm{A}=0.56$. All these parameters are unitless. Validation of these parameters by comparing numerical with experimental tests on elastomeric bearings as well as more details about the strain energy function (Eq. (1)) that describes the material were presented by Kalfas et al. (2017b), where a very similar approach was used. The values of the hyperelastic and hysteretic parameters are summarised in Table 2.

The cyclic shear loading generates a hysteresis loop, which is not related to the Mullins effect (Mullins 1969). During the first cycles of the bearing loading, there is a reduction of the bulk modulus of the elastomer, due to the Mullins effect (Mullins 1969; Diani et al. 2009; Ragni et al. 2018). The Mullins effect occurs predominantly during the first cycle of loading, whilst the reduction of the bulk modulus of the elastomer is incrementally smaller during the subsequent cycles, up until the stabilisation in the hysteresis (Diani et al. 2009). However, for this study, the bearings were considered scragged, and the Mullins effect was not taken into consideration, given that there are continuous cyclic movements of the bearings, due to the thermal expansion and contraction of the deck. Although cavitation in the elastomer and delamination at the steel-elastomer interfaces are potential damage states in steel laminated elastomeric isolators, the modelling of these phenomena present exceptional challenges and is outside the scope of this study, which focuses on the behaviour of the steel shims and their influence on the response of the isolators. 
Regarding the mechanical characteristics of the steel anchor plates and shims, the Young's modulus was taken as $2.1 \times 10^{5} \mathrm{MPa}$, for steel grade S235, which is typical for steel-reinforced elastomeric bearings as per EN 1337-3 (2005). The steel plasticity was accounted for based on Faridmehr et al. (2014) through the uniaxial stress - strain relationship shown in Fig. 2, where the value of $235 \mathrm{MPa}$ indicates the yielding point.

Table 2. Material and mechanical properties of the elastomer, the steel shims and the anchor plates of the steelreinforced elastomeric bearings.

\begin{tabular}{|c|c|c|c|c|c|}
\hline & & & & $\begin{array}{l}\text { notation } \\
\text { (unit) }\end{array}$ & value \\
\hline \multirow{12}{*}{$\begin{array}{c}\text { elastomeric } \\
\text { layers }\end{array}$} & \multirow{4}{*}{\multicolumn{2}{|c|}{$\begin{array}{l}\text { hyperelastic } \\
\text { coefficients }\end{array}$}} & \multirow{2}{*}{$\begin{array}{c}\text { initial stiffness } \\
\text { parameters }\end{array}$} & $\mu_{1}(\mathrm{MPa})$ & 0.41 \\
\hline & & & & $\alpha_{1}$ & 1.6 \\
\hline & & & post-elastic stiffness & $\mu_{2}(\mathrm{MPa})$ & 0.0012 \\
\hline & & & parameters & $\alpha_{2}$ & 6.2 \\
\hline & \multirow{5}{*}{$\begin{array}{c}\text { Ogden } \\
\text { parameters }\end{array}$} & \multirow{5}{*}{$\begin{array}{l}\text { hysteretic } \\
\text { parameters }\end{array}$} & stress scaling factor & $\mathrm{S}_{\mathrm{SF}}$ & 1.6 \\
\hline & & & creep strain exponent & $\mathrm{C}$ & -1 \\
\hline & & & effective stress & & \\
\hline & & & exponent & $\mathrm{m}$ & 4 \\
\hline & & & creep parameter & A & 0.56 \\
\hline & \multirow{3}{*}{\multicolumn{2}{|c|}{ mechanical properties }} & shear modulus & $\begin{array}{c}\mathrm{G}_{\mathrm{b}} \\
(\mathrm{MPa})\end{array}$ & 0.664 \\
\hline & & & Poisson's ratio & $v$ & 0.4998 \\
\hline & & & bulk modulus & $\mathrm{B}(\mathrm{MPa})$ & 1000 \\
\hline \multirow{2}{*}{$\begin{array}{l}\text { steel shims } \\
\text { \& anchor } \\
\text { plates }\end{array}$} & \multicolumn{3}{|c|}{ Young's modulus } & $\mathrm{E}(\mathrm{MPa})$ & 210000 \\
\hline & \multicolumn{3}{|c|}{ Poisson's ratio } & $v$ & 0.3 \\
\hline
\end{tabular}

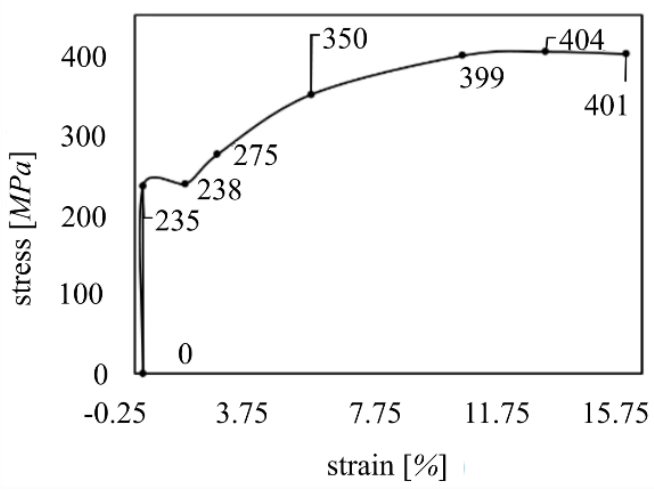

Fig. 2. Stress-strain curve for steel grade S235. 
To achieve convergence in the analyses whilst maintaining a reasonable computational time, a sensitivity analysis was conducted to select the most appropriate element type for the parts of the models. It was decided to use the C3D6 wedge elements in ABAQUS/CAE (6-node triangular prisms) for the central part of the bearings, whilst the remaining parts of the rubber layers were modelled using the C3D8R brick elements (three-dimensional 8node parallelepipeds with reduced integration). These types of elements were chosen due to the aimed reduction in the computational time, because the "reduced integration" elements use fewer Gauss integration points. A total of 33600 elements were used for the modelling of $\mathrm{B}_{1}, \mathrm{~B}_{2}, \mathrm{~B}_{4}$, and $\mathrm{B}_{6}$. The five steel shims were meshed with 16800 elements, the six elastomeric layers with 10080 elements, and the two anchor plates with 6720 elements. Geometric nonlinearities were incorporated into the analysis. The interface between the rubber layers and the steel shims, as well as between the top and bottom plate and the rubber layers was modelled as tie-type constraint, which enforces identical displacements and rotations for points in contact. For the analyses, fixed boundary conditions were chosen for the bottom surface of the lower anchor plate, i.e. $U X=U Y=U Z=R X=R Y=R Z=0$. Three different groups of boundary conditions were used for the top surface of the upper anchor plate related to realistic bridge bearing loading scenarios (Fig. 3): (a) restraint against translation in the $\mathrm{x}$-direction $(\mathrm{UX}=0)$ and against rotations about the horizontal and the vertical axes $(R X=R Y=R Z=0),(\mathrm{b})$ restraint against translation in the $\mathrm{x}$-direction $(U X=0)$ and against rotation about the $\mathrm{y}$ - and $\mathrm{z}$-axis $(R Y=R Z=0)$, and (c) no restraints of the upper anchor plate, i.e. the bearing is allowed to rotate about the horizontal and the vertical axes. These three groups of boundary conditions are hereinafter denoted as GR1, GR2 and GR3, respectively. The restraint of the translations and rotations was applied by allowing zero movement along and about these axes, respectively. Figure 3 depicts the three different groups of boundary conditions and local axes system. These groups of analyses (GR1, GR2, GR3) cover a wide range of bearing rotations. GR1 represents the case where the isolator's top anchor plate has zero rotation, achievable only if the superstructure provides infinite rotational stiffness. GR3 represents the case where the superstructure provides negligible rotational stiffness, which apparently leads to large tensile stresses (Kalfas et al. 2017b). These two extreme cases are used to provide a range of the expected responses of the isolators. GR2 represents the most realistic scenario where the superstructure provides a finite rotational stiffness. Regarding the applicability of the chosen boundary conditions, the support rotations are negligible in most building applications, owing to the large flexural rigidity of the 
structural elements above and below the isolation layer, similar to what GR1 represents. GR2 and GR3 conditions are more realistic in bridge and other applications, such as mid-story isolation, where rotations are expected. As modelling of the superstructure goes beyond the scope of this study, it is assumed that the rotation of the top plate about the $\mathrm{x}$-axis (Fig. 3b) follows the same history as the shearing displacement, reaching a maximum value of $\mathrm{RX}=0.025$ radians. Such rotations are high but realistic considering the relatively low shape factor of the bearing $(S=9)$, which was considered in this study, together with the results found in Mitoulis (2014) and Crowder and Becker (2017). The latter research considered shape factors of $S=20$, i.e. bearings that had significantly greater rotational stiffness than the ones analysed in this paper. It is also underlined that the rotation of the upper support of the steel-reinforced elastomeric bearings is an important loading parameter, which influences the lateral behaviour of the bearing and should be taken into consideration according to research findings (Forcellini et al. 2017; Kalfas and Mitoulis 2017; Rastgoo Moghadam and Konstantinidis 2017).

Regarding the loading conditions of the analyses, axial loading to the upper anchor plate of the bearings was applied initially as an instant load along the z-axis, followed by shear displacement along the y-axis, whilst the axial load had been kept constant, with the bottom anchor plate being fixed. A shear strain (defined as the ratio of the horizontal displacement of the top plate to the total thickness of the rubber, $T_{r}$ ) of $150 \%$ was imposed to the isolator. The model isolators were subjected to two full cycles of loading-unloading to a $99 \mathrm{~mm}$ shear displacement. The sequence of the applied shear strain is illustrated in Fig. 4a together with the simultaneous rotations about the x-axis for GR2 (Fig. 4b). Different axial loads were applied to the models, prior to the application of the shear strains. The axial loads corresponded to average pressures of $-2 \mathrm{MPa}$ (tension), $0 \mathrm{MPa}, 2$ $\mathrm{MPa}, 5 \mathrm{MPa}, 7 \mathrm{MPa}$, and $10 \mathrm{MPa}$. It is noted that the axial loads remained constant throughout the shearing of the bearings. Different analyses were conducted for each axial load. Finally, for the second group of boundary conditions, a sawtooth rotation loading history of 0.025 radians amplitude (about the x-axis in Fig. 3), which is relatively higher than the cyclic rotation expected in practice (Stanton et al. 2007), was applied simultaneously with the shear strain, as shown in Fig. 4b. Thus, three groups of 24 nonlinear static analyses were performed, i.e. a total of 72 simulations.

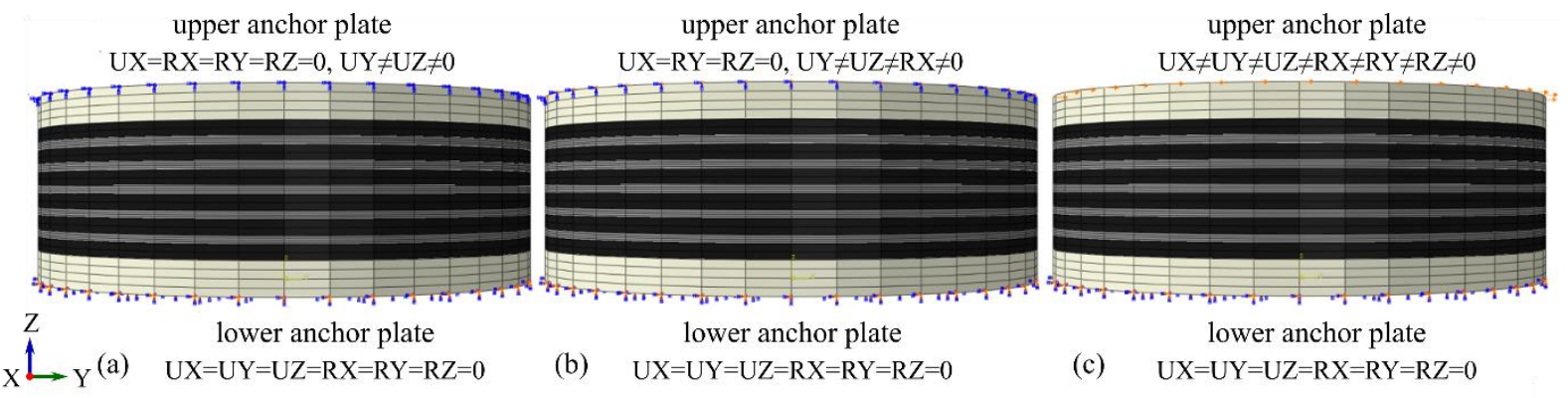


Fig. 3. The boundary conditions of the upper and lower anchor plates for (a) GR1, (b) GR2 and (c) GR3 groups of analyses.

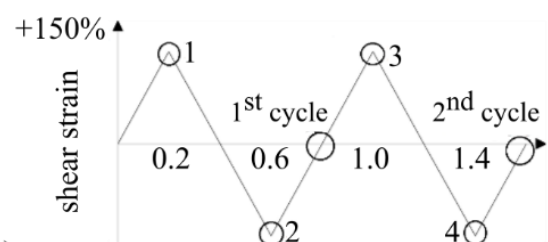

(a) $-150 \%$

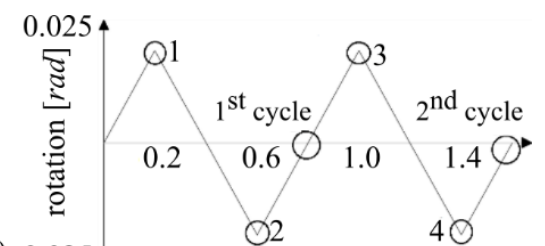

(b) 0.025

Fig. 4. The loading pattern of the two cycles of pseudo-static loading: (a) shear strain and (b) rotation sequence.

\section{EFFECT OF THE STEEL SHIM THICKNESS ON THE VULNERABILITY OF THE}

\section{ELASTOMERIC BEARINGS}

\subsection{Influence of the thickness of the steel shims on their plasticity and the residual axial deflections under} the maximum allowable shear strains

The response of the internal steel shims of rubber bearings under the combination of axial and shear loads is affected by the thickness of the steel shims. The plasticity of the steel shims is assessed with the plasticity ratio $r_{p l}$, expressed as:

$$
r_{p l}=\frac{\sigma}{\sigma_{p l}}
$$

where $\sigma$ is the developed maximum value of the Von Mises stresses among all the points in the mesh of the steel shims at the target shear displacement of the first and the second cycles of loading $(+150 \%$, points 1 and 3 in Fig. 4a); and $\sigma_{p l}$ is the yielding stresses as shown in Fig. 2 (i.e. $235 \mathrm{MPa}$ ). The Von Mises are considered as an effective measure for representing the damage ratio of a ductile material like steel. In this case, $r_{p l} \geq 1$ (Eq. (2)) represents 'failure' based on the Von Mises failure criterion. The fact that the FE software predicts spikes in the stresses is considered by reviewing the results of the Von Mises stresses so that the maximum is not erroneously recorded at a stress spike, that can corrupt the conclusions. A sensitivity analysis with substantially denser mesh was conducted to verify that the peak stresses calculated are not dependent of the density of the mesh, and indeed the results were very similar, which is evidence that these peaks affect only a negligible part of the steel shims, and hence do not influence the global response of the bearing. Figure 5 depicts the plasticity ratios of all the steel shims of all the different models, $\mathrm{B}_{1}-\mathrm{B}_{6}$. The stresses are recorded at $+150 \%$ of the shear displacement during 
the first (Fig. 4, point 1) and the second (Fig. 4, point 3) cycles of loading under $10 \mathrm{MPa}$ of axial compression. The three different boundary conditions (GR1, GR2 and GR3) are considered. It is observed that the different boundary conditions affect the steel shim plasticity during the first cycle of loading. Comparing the graphs of Fig. $5 \mathrm{a}$, it is observed that the thinner the steel shims the higher the plasticity ratio. In particular, $\mathrm{B}_{1}$ experiences a plasticity ratio higher than one (i.e. the Von Mises stresses have exceeded the yielding value) that is more evident at the lower (SS1) and the upper (SS5) steel shims, whilst the middle ones (SS2-SS4) experience a plasticity ratio closer to one. The reason for the concentration of damage into the top and bottom steel shims is that when a bearing is sheared, a bending moment distribution develops along its height, with maximum values attained at the top and bottom supports. This, in turn, results in the rotation of the shims at the top and bottom to become maximum. These large rotations impose large pressures in the confined rubber and consequently large in-plane stresses in the shims. In contrast, the thicker steel shims $\left(\mathrm{B}_{2}-\mathrm{B}_{6}\right)$ exhibit better performance at the lower shims, whilst the upper ones (SS5) exceed the yielding value. With regard to the influence of the boundary conditions, it is observed that for all the multiple thicknesses of the steel shims, the bearings behave better when the upper anchor plate is restrained (GR1). In the case of the non-fixed upper anchor plate (GR3), the upper steel shim of all the different thicknesses exhibits damage that deteriorates the behaviour of the bearing. This does not necessarily mean that the isolator cannot perform, but in the cases where the upper and lower plates of the bearings are not fixed, they should be considered in planned inspections and maintenance. On the other hand, based on Fig. $5 b$, it can be seen that the thinner steel shims $\left(\mathrm{B}_{1}\right.$ and $\left.\mathrm{B}_{2}\right)$ have more extensive yielding, i.e. the plasticity ratio is larger than in Fig. 5a. It can also be seen that more steel shims have yielded compared to what was discussed previously, where only the lower and the upper shims yielded. Moreover, $\mathrm{B}_{4}$ and $\mathrm{B}_{6}$ appear to have larger plasticity ratios values compared to the ones during the first cycle of loading, but only the two ends (SS1 and SS5) have yielded significantly and only for the GR3 boundary conditions. The various boundary conditions affect the plasticity ratio of the bearings in the same manner as they did during the first cycle, i.e. the steel shims are more affected when the upper support is allowed to rotate. It is therefore concluded that the thickness of the steel shims affects their plasticity, and the boundary conditions are important in order for the isolator to avoid damage and especially for the steel shims that are more susceptible to yielding. The multiple cycles of loading deteriorate the performance of the bearings as they increase the plasticity ratios of the steel shims. It is seen in Fig. 5 that the plasticity ratio value increases during the second cycle of loading and additionally, more steel shims are affected than the obvious upper and lower ones. 
In this study, the propagation of yielding to the area of the shim is accounted for. For the cases where the plasticised region is limited, e.g. when an individual element exceeds the yielding value, this does not necessarily mean poor overall performance. For these cases, the shims are recorded as unaffected. Hence, it is understandable that design-wise it is safer to have thicker steel shims within elastomeric bearings as this minimises the plasticity and as such the damage. Nevertheless, an increase in the steel shims will increase the cost and weight of the isolator. A compromise in design terms would be to use thicker steel shims for the first and the last plate. It is also clear that it is preferable to minimise the rotations of the elastomeric bearings justifying, in engineering terms, the common choice of a stiff interface that minimises rotations in isolated structures.
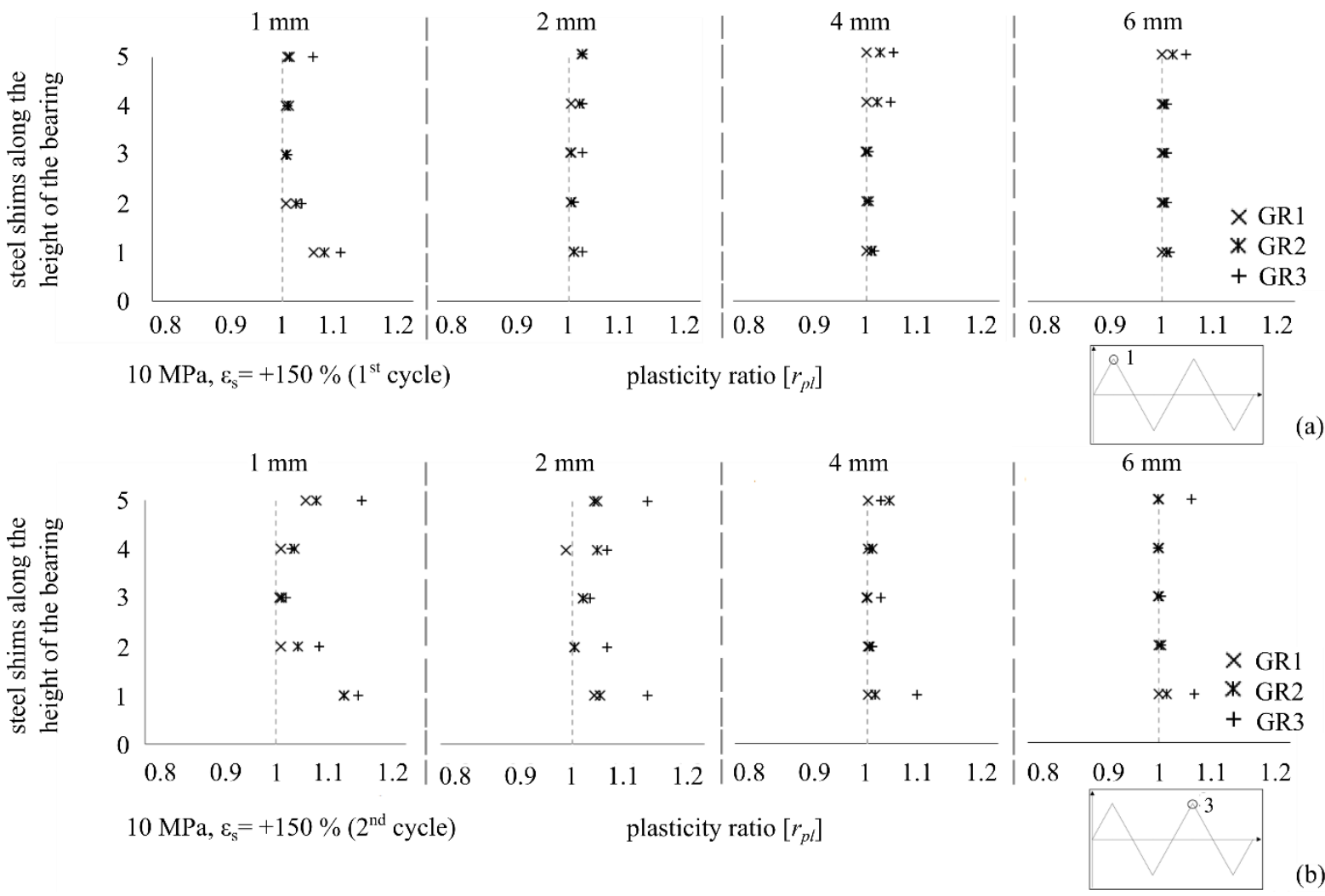

Fig. 5. Plasticity ratios of the steel shims of models $B_{1}-B_{6}$ under $10 \mathrm{MPa}$ of axial compression for different boundary conditions, at the shear displacement of $\varepsilon_{s}=150 \%$, as per Fig. 4: (a) first cycle and (b) second cycle.

Figure 6 illustrates the distribution of the Von Mises stresses within the five steel shims (SS1 to SS5 from bottom to top) of Model $\mathrm{B}_{4}$ under $10 \mathrm{MPa}$ of average pressure. This is considered the reference case. The positions of the different steel shims can be seen in Fig. 1. The three different boundary conditions (GR1, GR2, GR3) are accounted for and the Von Mises stresses are recorded at the target shear displacement $(+150 \%)$ of the first and the second cycles of loading (points 1 and 3 in Fig. 4). The areas with the grey colour that can be seen in the horizontal sections of the steel shims are the ones where the yielding value is exceeded, i.e. damage is detected. 
331 A comparison between the maximum values of the Von Mises stresses developed in the steel shims for the three 332 different boundary conditions, shows that the GR1 group (Fig. 6a - with the fixed upper support) leads to 333 development of smaller maximum values compared to the other two groups, GR2 (Fig. 6b - partially restraint of the upper support rotations) and GR3 (Fig. 6c - free upper support). It is also observed that the number of steel shims that appear to yield vary, depending on the upper support rotation. In particular, only SS1 is yielded when the GR1 group of boundary conditions is applied, the steel shims SS1-SS3 when GR2 group is applied and SS1SS4 when GR3 group is applied. Hence, a larger number of steel shims yield if the upper bearing plate is free to translate and rotate, whilst the number of the steel shims that are affected is reduced to three when the upper anchor plate is partially restrained (GR2). In the case where the upper anchor plate is not allowed to rotate (GR1), only the lower steel shim yields. Practically, this means that the restraint of the upper support rotation keeps the bearings undamaged. In terms of the values of the development of the Von Mises stresses, these are increased by $5 \%$ and $7 \%$ when the boundary conditions change from GR 1 to GR2 and from GR 1 to GR3, respectively. Finally, it is noticed that the maximum stresses in the lower steel shims are higher, but when the area that yields is compared then the lower the steel shims (SS1) the smallest the area that is affected (SS2-SS4). The development of the Von-Mises stresses when smaller values of compression were applied to the bearings is similar to Fig. 6. The values of the stresses on these occasions are smaller compared to the ones under pressure of $10 \mathrm{MPa}$. 
Von Mises stresses at the target shear displacement (+150\%) of model B4:
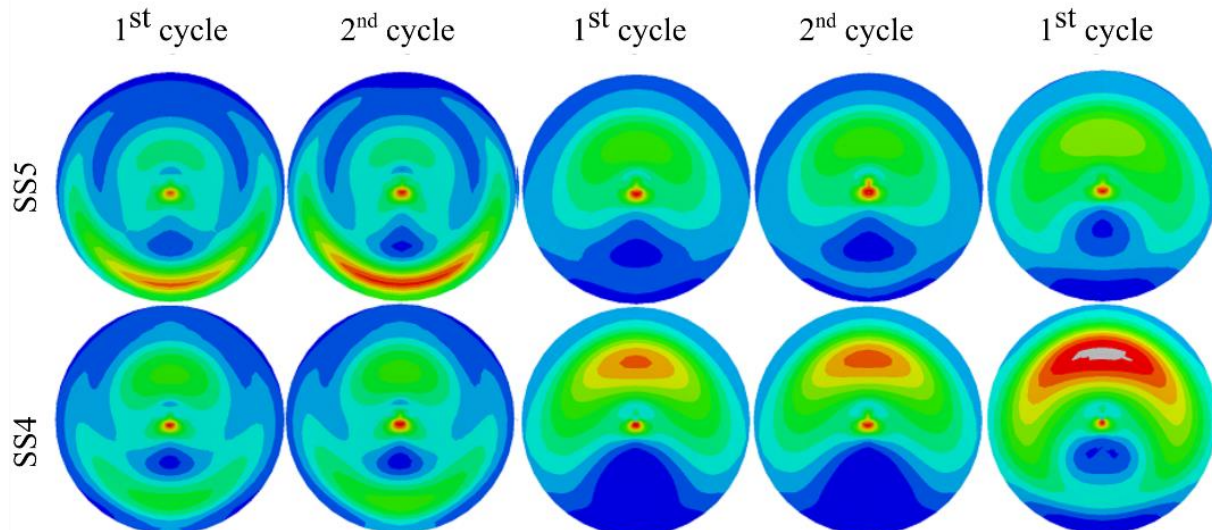

$2^{\text {nd }}$ cycle
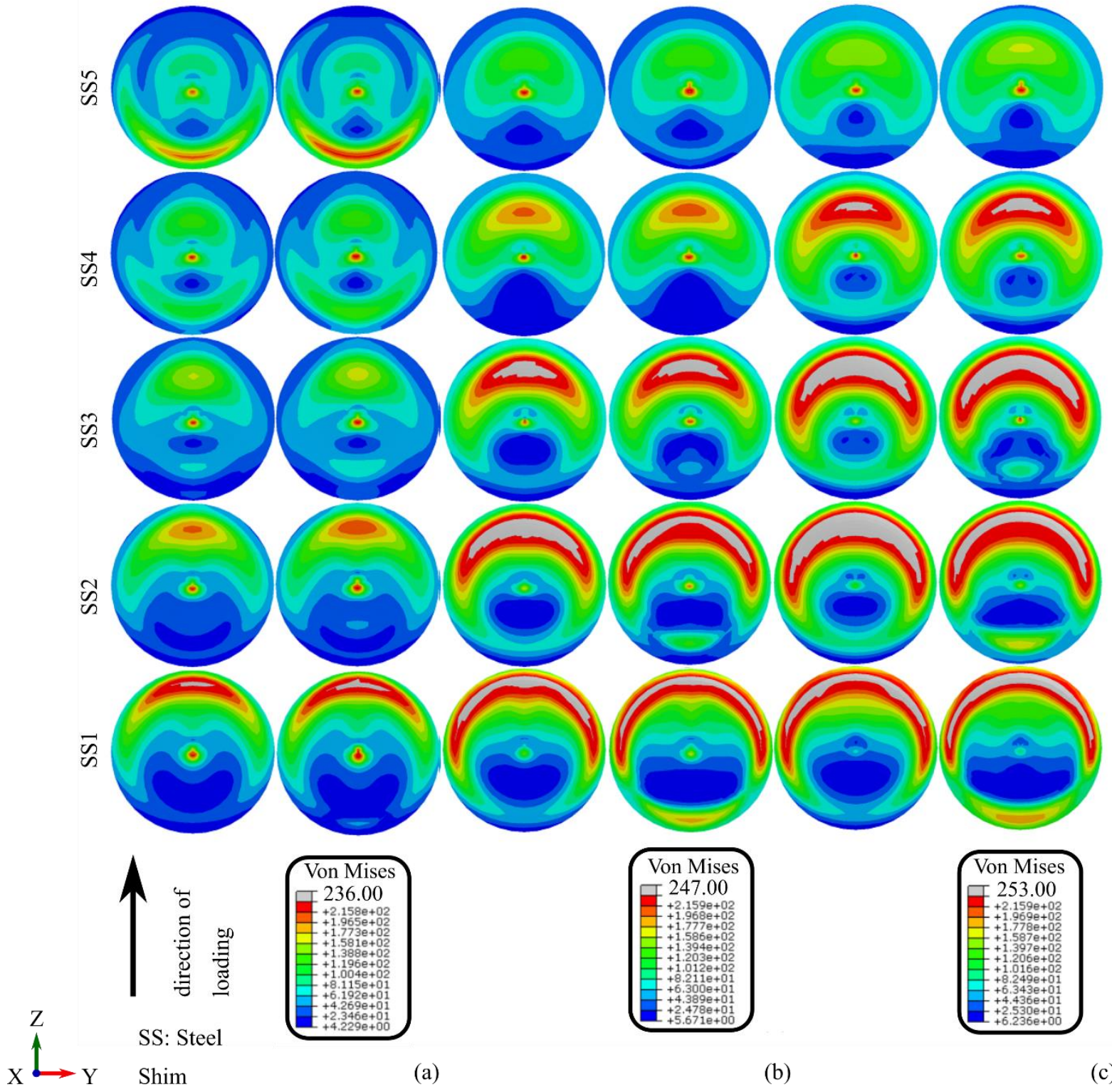

SS: Steel
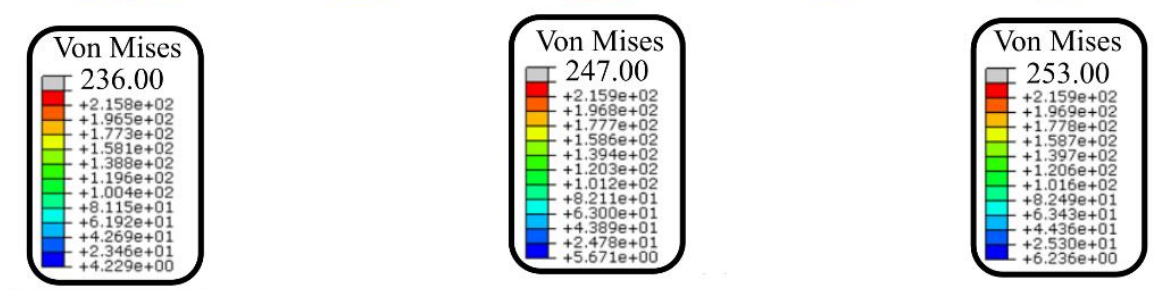

(a)

(b)

(c)

Fig. 6. Development of the Von Mises stresses in the steel shims of model $\mathrm{B}_{4}$ under $10 \mathrm{MPa}$ of axial compression at the shear displacement (150\%) of the first and the second cycles of loading. Horizontal sections of the different steel shims, for the three different groups of boundary conditions: (a) GR1, (b) GR2 and (c) GR3.

Figure 7 illustrates the vertical deflections at the left edge, the midpoint, and the right edge of the upper steel shim (SS5) at different stages during the two cycles of loading-unloading. The points where the deflections are recorded are indicated with circles in Fig. 7. Models $\mathrm{B}_{1}$ (Figs. 7a and 7b) and $\mathrm{B}_{6}$ (Figs. 7c and 7d) are chosen for this comparison under $10 \mathrm{MPa}$ of axial compression. The groups that are compared are GR2 (Figs. 7a and 7c) and GR3 (Figs. 7b and 7d), given that GR1 allows no translations or rotations of the upper support and this minimises 
possible deflections and rotations of the steel shims that move almost parallel to the upper support. The initial deflection under pure compression of $10 \mathrm{MPa}$ is $1.35 \mathrm{~mm}$ for $\mathrm{B}_{1}$, whilst the corresponding deflection for $\mathrm{B}_{6}$ is 1.3 mm. A comparison between Figs. 7a and 7c shows that the deflections of the upper steel shim at each shear displacement (not under pure compression which was the case previously) are almost the same, with a negligible decrease for $\mathrm{B}_{6}$ in some cases (e.g. the deflections at the middle of the upper steel shims at $+150 \%$ shear displacement of the first and the second cycles). However, this is not the case when models $\mathrm{B}_{1}$ and $\mathrm{B}_{6}$ are compared with the GR3 group. In that case, the thicker steel shims appear to decrease the axial permanent deflections, at the end of the two cycles of loading-unloading, up to $12 \%$. These permanent deflections are likely due to permanent distortion of the shims that could be either stretching or bending of them. Thus, the thicker the steel shims the smaller the deflections. By comparing the deflections between the first and the second cycles of loading-unloading, for the same shear displacement (e.g. in Fig. $7 \mathrm{a}$, the deflections of $+150 \%$ of the first and the second cycles are compared), it is observed that these are increased during the second cycle. This is likely attributed to cumulative plastic strain in the shims after two successive cycles of loading-unloading, a finding that is further justified by the plasticity ratio results shown in Fig. 5. When the different boundary condition groups are compared, it can be said that the freer the upper bearing plate, the greater the steel shim deflections. More specifically, for the $\mathrm{B}_{1}$ model at the maximum shear displacement of $+150 \%$, where the imposed rotation for GR2 is $0.025 \mathrm{rad}$ (Fig. 7a) and the corresponding one for GR3 is zero (Fig. 7b), there is an increase of the axial deflections at the middle point of the bearing from GR2 to GR3 of $13 \%$ and $15 \%$ during the first and the second cycles, respectively. The corresponding increases when $\mathrm{B}_{6}$ model is considered (Figs. 7c and 7d), are $7 \%$ and $7 \%$. Finally, it is also observed that at the end of the two cycles of loading-unloading, irrespectively of the boundary conditions of the top bearing plate or the steel shim thickness, there are permanent deflections recorded. The percentage of the remaining deflections at the middle point of the bearing of the upper steel shim (i.e. at the end of the second cycle) with respect to the deflections at the target shear displacement $(+150 \%)$ of the first cycle of loading is $68 \%, 63 \%, 71 \%$ and $67 \%$ from Figs. 7a, 7b, $7 \mathrm{c}$ and $7 \mathrm{~d}$, respectively. These permanent deflections suggest inelastic behaviour of the steel shims under the design shear strains. 


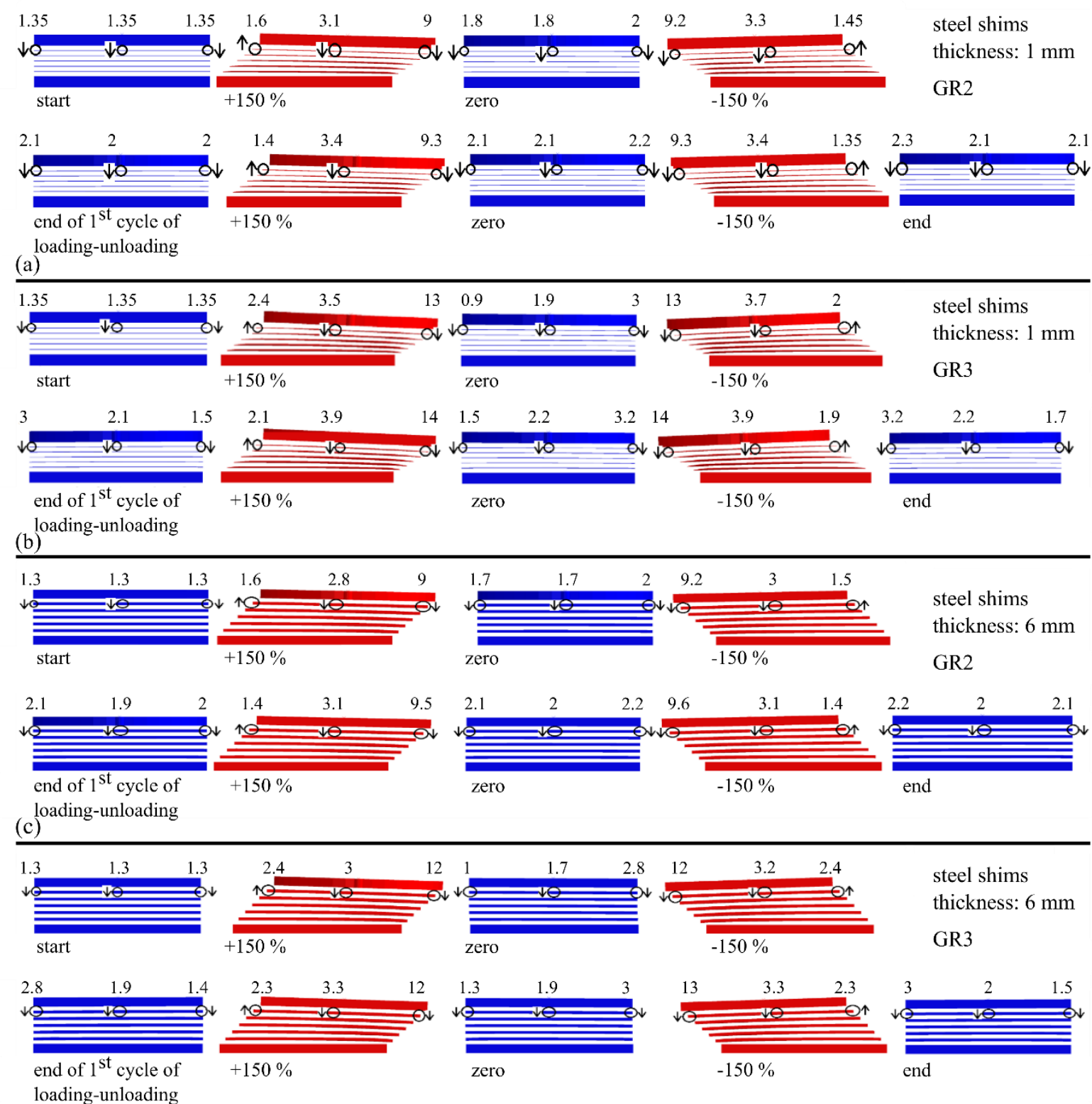
(d)

383 Fig. 7. Vertical deflections (in $\mathrm{mm}$ ) of the upper steel shim throughout the two cycles of loading-unloading.

384 Elevations of $\mathrm{B}_{1}$ and $\mathrm{B}_{6}$ models. Two different groups of boundary conditions GR2 ((a) and (c)) and GR3 ((b) and (d)) (pressure $10 \mathrm{MPa})$.

\subsection{Effect of steel shim thickness on the vulnerability of elastomeric bearings}

The energy dissipation capability of low-damping natural rubber is typically insufficient to control the displacements of the seismic isolation system within acceptable practical limits. For this reason, supplemental

391 damping devices (such as fluid, metallic, or friction dampers) are used in conjunction with low-damping natural rubber isolators. The steel shims of the steel-reinforced elastomeric bearing are expected to remain essentially 
elastic, at least for design-level earthquake displacements. Damage due to yielding in the shims occurs in the interior of the bearing, and it is therefore very difficult to observe. To ascertain the vulnerability of rubber bearings to damage due to yielding in the steel shims, this study adopts the damage factor proposed by Camara et al. (2017) for distinguishing the damage in different structural members:

$$
\Omega=\sum_{j} \Omega_{j}=\sum_{j} \frac{E_{S p, j}}{E_{W}}
$$

where, in this study, $j$ increments over the steel shims; $E_{S p, j}$ is the plastic energy dissipation, i.e. the energy dissipation due to the plastic deformation of the $\mathrm{j}^{\text {th }}$ steel shim, of the multiple models $\mathrm{B}_{1}, \mathrm{~B}_{2}, \mathrm{~B}_{4}$ and $\mathrm{B}_{6}$ at the end of the full cycle of loading-unloading, i.e. the accumulation of the yielding of the steel shims, and $E_{W}$ is the input energy derived from the application of the displacements, the axial loads and the rotations (i.e. the work due to the external forces).

Figure 8 depicts the damage factor of all the models $\mathrm{B}_{1}-\mathrm{B}_{6}$ following the completion of the full cycle of loadingunloading. The different combinations of the applied loading and the groups GR1 and GR2 of boundary conditions are considered. Group GR3 is not considered herein. It is observed in Fig. 8 that the increase of the steel shims thickness decreases the induced damage to the isolator steel shims. This is evident for both the groups of the upper support boundary conditions (GR1 - Fig. 8a and GR2 - Fig. 8b) and for all the different applied axial loads. More specifically, for GR2 (Fig. 8b), when the imposed axial tensile or compressive load is small (-2 MPa, $0 \mathrm{MPa}$ or 2 $\mathrm{MPa}$ ) there is almost negligible damage of less than $0.5 \%$. When the axial compression is $5 \mathrm{MPa}$, the decrease of the damage of the isolators, when the steel shim thickness increases from $1 \mathrm{~mm}$ to $2 \mathrm{~mm}$, is $31 \%$ and the corresponding decrease when the steel shim thickness increases from $2 \mathrm{~mm}$ to $4 \mathrm{~mm}$ and from $4 \mathrm{~mm}$ to $6 \mathrm{~mm}$ is $22 \%$ and $30 \%$, respectively.

When the influence of the upper support rotation is considered, it is observed that for GR1 (Fig. 8a) the maximum damage of the isolators (3\%) appears in the $\mathrm{B}_{1}$ model subjected to $10 \mathrm{MPa}$ of axial compression. By comparison, for GR2 (Fig. 8b) the damage factor is smaller than $10 \%$ for $5 \mathrm{MPa}$ of axial compression, whilst for $7 \mathrm{MPa}$, the damage factor varies from $13 \%$ to almost $20 \%$. For $10 \mathrm{MPa}$ and GR2, the damage factors vary from $37 \%$ to almost $50 \%$. These values show that when the upper support rotation is fixed (GR1) then the shims, and consequently the bearings, remain elastic, in contrast to the case where partially restraint of the upper support (GR2) is provided. It can be said that as the axial compression is increased, the level of damage in the shims grows dramatically. Bearings with thick steel shims (e.g. $\mathrm{B}_{6}$ ) and rotation fixity at the top support will most probably have negligible damage under axial compressions up to $10 \mathrm{MPa}$. 
It can be extracted that for compression of $5 \mathrm{MPa}$ and $7 \mathrm{MPa}$, for GR1, only $\mathrm{B}_{1}$ and $\mathrm{B}_{2}$ models are slightly damaged, but the damage is limited, i.e. less than $0.5 \%$. When the axial compression is $10 \mathrm{MPa}$, the models have damage levels ranging from $0.7 \%$ up to $3.1 \%$, i.e. the boundary conditions of the upper anchor plate retain the bearings undamaged in most of the cases.

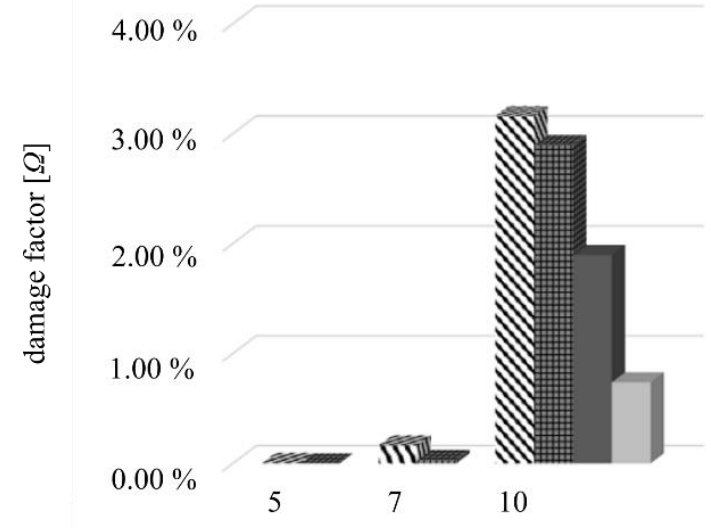

(a)

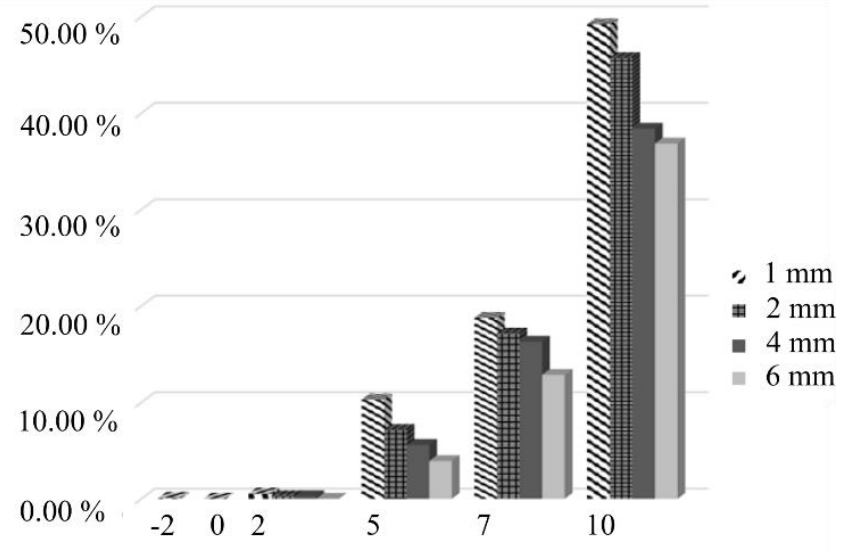

(b) average vertical stress $[M P a]$

Fig. 8. Damage factor $(\Omega)$ of the isolators of groups (a) GR1 and (b) GR2 under the combination of shear displacements and variable axial loads.

\subsection{Effect of steel shim thickness on the performance of elastomeric bearings}

The influence of the steel shim thickness on the behaviour of the elastomeric bearings is studied by comparing the effective stiffness and damping ratio of models $\left(\mathrm{B}_{1}-\mathrm{B}_{6}\right)$ under $5 \mathrm{MPa}$ of compressive load and different boundary conditions (GR1 - GR3). Table 3 shows the effective stiffness and the damping ratio of the aforementioned cases. The effective stiffness, $K_{\text {eff }}$, hereinafter referred to as stiffness, is computed at the maximum shear displacement $(+150 \%)$. The corresponding effective damping ratio is calculated using

$$
\xi_{e f f}=\frac{W_{D}}{2 \pi K_{e f f} D^{2}}
$$

where $W_{D}$ is the area of the hysteresis loop (energy dissipated per cycle) and $D$ is the displacement amplitude.

Figure 9 illustrates the shear stress-strain curves of the multiple models $\left(B_{1}-B_{6}\right)$ - where shear stress is the average stress computed by dividing the resulting reaction forces over the area of the isolator. It is observed in Table 3 and in Fig. 9 that the behaviour of the bearings does not depend on the thickness of the steel shims for any given group of boundary conditions. More specifically, the stiffness with respect to the different thicknesses is almost the same when the upper anchor plate is fully or partially restrained from rotation (GR1 and GR2). In these cases, 
there appears to be a negligible decrease of the stiffness when the thickness of the steel shims increases. In addition to these results, when the upper anchor plate is free to rotate (GR3) then the increase of the thickness of the steel shim results in negligible higher stiffness. Hence, the increase of the steel shim thickness does not result in higher values of the stiffness of the bearings.

The thickness of the steel shims does not influence the damping of the elastomeric bearings. In particular, the thicker the steel shims the smaller the damping ratio, but this is observed only in the cases of the free upper anchor plate to rotate and translate (GR3). Thus, it can be concluded that the steel shim thickness does not influence the damping capacity of the bearings. Both observations, i.e. the influence of the stiffness and the damping of the bearings from the steel shim thickness, are in line with the previous study by Kelly and Takhirov (2001), where they concluded that there is only a minuscule change to the stiffness of the bearings due to variation in the thickness of the steel shim.

Table 3. Effective stiffness and damping ratio, of models $\mathrm{B}_{1}-\mathrm{B}_{6}$ under combination of shear displacements and 5 MPa of axial compression for different top-support boundary conditions.

\begin{tabular}{cccccc}
\hline \hline \multicolumn{2}{c}{ steel shim thickness } & $1 \mathrm{~mm}$ & $2 \mathrm{~mm}$ & $4 \mathrm{~mm}$ & $6 \mathrm{~mm}$ \\
\hline \multirow{2}{*}{ GR1 } & $\mathrm{K}_{\text {eff }}(\mathrm{kN} / \mathrm{m})$ & 1206 & 1204 & 1204 & 1204 \\
\cline { 2 - 6 } & $\xi_{\text {eff }}(\%)$ & 12.6 & 12.6 & 12.5 & 12.5 \\
\hline \multirow{2}{*}{ GR2 } & $\mathrm{K}_{\text {eff }}(\mathrm{kN} / \mathrm{m})$ & 1092 & 1086 & 1082 & 1083 \\
\cline { 2 - 6 } & $\xi_{\text {eff }}(\%)$ & 13.2 & 13.3 & 13.3 & 13.2 \\
\hline \multirow{2}{*}{ GR3 } & $\mathrm{K}_{\text {eff }}(\mathrm{kN} / \mathrm{m})$ & 1073 & 1066 & 1071 & 1079 \\
\cline { 2 - 6 } & $\xi_{\text {eff }}(\%)$ & 14.0 & 14.1 & 14.0 & 13.8 \\
\hline \hline
\end{tabular}
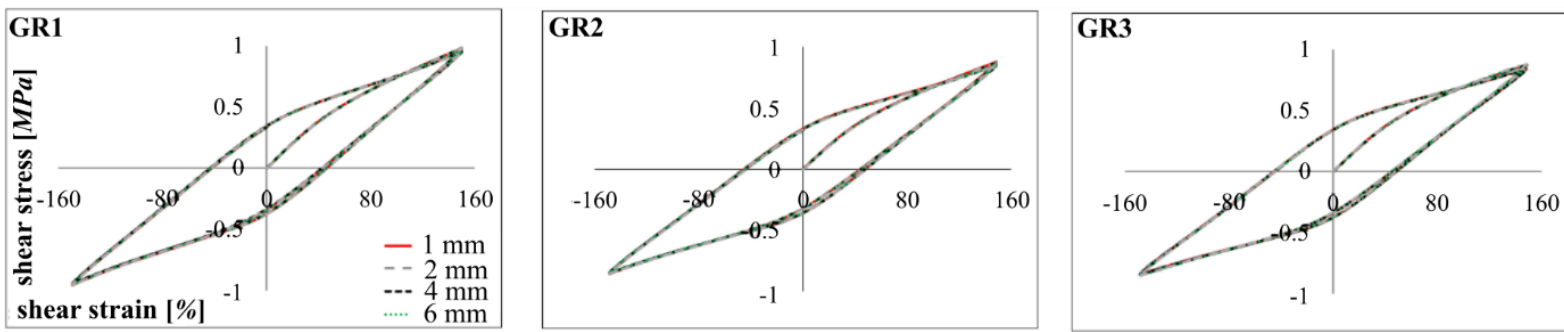

Fig. 9. Response of the elastomeric bearings under the combination of shear displacements and $5 \mathrm{MPa}$ of axial compression with different steel shim thickness considering the rotation of the bearings.

\section{INFLUENCE OF THE TOP SUPPORT ROTATION ON THE BEHAVIOUR OF THE} ELASTOMERIC BEARINGS

\subsection{Permanent movements of the upper anchor plate after multiple cycles of loading}


470 The relative rotation between the upper and lower anchor plates influences the lateral behaviour of the elastomeric bearings significantly. In addition, a resilient design with isolators should include bearings that have re-centring capabilities and thus estimating the permanent deflections of the isolators is important. Figure 10 illustrates a section of one of the models during the initial undeformed condition (no load has been exerted on it) where the location of the recorded axial deflections is shown. This location was chosen as the location exhibiting maximum deflections when the combination of shear displacements, axial loads and rotations are exerted on the isolator. This response quantity is of importance, since this will give the worst-case scenario of the rotation of the upper bearing plate. The influence of the thickness of the steel shims on the deflections of the upper anchor plate (and

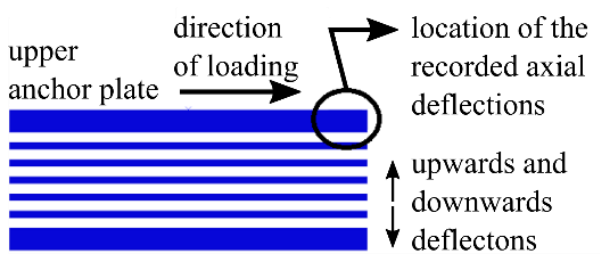

Fig. 10. Indicative vertical section of one of the models with the location of the recorded axial deflections.

consequently on the rotation of them) is discussed here. Table 4 summarises the axial deflections of the upper anchor plate of bearings $B_{1}$ to $B_{6}$ for GR2 (Fig. 3b) under various combinations of shear displacement, applied rotation and axial load values. The axial deflections of the upper anchor plate are recorded at instants 1 and 3 (Fig. 4), i.e. at the maximum shear displacement of $150 \%$ and maximum rotation of 0.025 radians of the upper bearing plate. Deflections are also recorded after the completion of the analyses, i.e. when the shear displacement is zero, to record residual deflections.

The upper anchor plate experiences axial deflections that range from $0.1 \mathrm{~mm}$ to $9.3 \mathrm{~mm}$, as can be seen in Table

4. There are permanent axial deflections at the end of the analyses which are up to $27 \%$ of the maximum observed ones when the axial compressive load is $10 \mathrm{MPa}$ for model $\mathrm{B}_{4}$. It is also observed that the thickness of the steel shims does not affect the axial deflection of the upper support significantly in the case of GR2. More particularly, there is a negligible reduction (of less than $2 \%$ ) of the axial deflections of the upper support when the steel shim thickness increases from $1 \mathrm{~mm}$ to $6 \mathrm{~mm}$. This is attributed to the fact that the partial restraint of the rotation of the upper support is adequate to maintain the relative rotation between the upper and lower anchor plates.

It is noticed that during the first (Fig. 4, point 1) and the second (Fig. 4, point 3) cycles of loading, the axial deflection of the upper support increases with the increase of the axial loads. This increase during the second cycle is relatively higher compared to the one during the first cycle. In particular, for model $\mathrm{B}_{4}$, there is a raise of the 
increase of the axial deflections of the upper support by $20 \%, 10 \%, 17 \%$ and $8 \%$, when the axial load is increased from 0 to $2 \mathrm{MPa}$, from 2 to $5 \mathrm{MPa}$, from 5 to $7 \mathrm{MPa}$ and from 7 to $10 \mathrm{MPa}$, respectively. Comparing the influence of the two cycles of loading-unloading on the of the axial deflections of the upper support, an increase of the axial deflections from the first to the second cycles at the shear displacements is observed in Table 4. This increase is negligible for compressions smaller than $7 \mathrm{MPa}$. When an axial compression of $10 \mathrm{MPa}$ is applied to model $\mathrm{B}_{4}$, then there is an increase of the axial deflection of the upper support from the first to the second cycles of loading, of $5 \%$. This is attributed to the cumulative effect of yielding of the steel shims with repeated cycling under higher compressive loads. The yielding of the shims results in increased lateral stretching of the rubber layers, but since the volume of the elastomer is conserved, the thicknesses of the rubber layers decrease and consequently, the upper anchor plate experiences a larger downward deflection. It can be said that the multiple cycles of loading increase the axial deflections of the upper anchor plate, but this increase is more pronounced for larger compressive loads.

Table 4. Axial deflection of the right corner of the upper anchor plate during subsequent cycles of loadingunloading for GR2.

\begin{tabular}{|c|c|c|c|c|c|c|c|}
\hline \multicolumn{2}{|c|}{$\begin{array}{l}\text { average vertical stress } \\
(\mathrm{MPa})\end{array}$} & $-2 \mathrm{MPa}$ & $0 \mathrm{MPa}$ & $2 \mathrm{MPa}$ & $5 \mathrm{MPa}$ & $7 \mathrm{MPa}$ & $10 \mathrm{MPa}$ \\
\hline \multicolumn{8}{|c|}{$\mathrm{B}_{1}$} \\
\hline \multirow{3}{*}{$\begin{array}{l}\text { shear } \\
\text { strain }\end{array}$} & $+150 \%$ & 5.6 & 6.2 & 6.7 & 7.6 & 8.1 & 8.9 \\
\hline & $+150 \%$ & 5.4 & 6.1 & 6.8 & 7.7 & 8.4 & 9.2 \\
\hline & 0 & 0.6 & 0.1 & 0.5 & 1.2 & 1.8 & 2.5 \\
\hline \multicolumn{8}{|c|}{$\mathrm{B}_{2}$} \\
\hline \multirow{3}{*}{$\begin{array}{l}\text { shear } \\
\text { strain }\end{array}$} & $+150 \%(1)$ & 5.6 & 6.2 & 6.7 & 7.6 & 8.1 & 8.8 \\
\hline & $+150 \%$ & 5.4 & 6.2 & 6.8 & 7.8 & 8.3 & 9.2 \\
\hline & 0 & 0.6 & 0.1 & 0.5 & 1.2 & 1.7 & 2.5 \\
\hline \multicolumn{8}{|c|}{$\mathrm{B}_{4}$} \\
\hline \multirow{3}{*}{$\begin{array}{l}\text { shear } \\
\text { strain }\end{array}$} & $+150 \%$ & 5.6 & 6.2 & 6.7 & 7.6 & 8.1 & 8.9 \\
\hline & $+150 \%$ (3) & 5.5 & 6.2 & 6.8 & 7.8 & 8.4 & 9.3 \\
\hline & 0 & 0.6 & 0.1 & 0.4 & 1.2 & 1.7 & 2.5 \\
\hline \multicolumn{8}{|c|}{$\mathrm{B}_{6}$} \\
\hline \multirow{3}{*}{$\begin{array}{l}\text { shear } \\
\text { strain }\end{array}$} & $+150 \%$ (1) & 5.7 & 6.2 & 6.7 & 7.6 & 8.1 & 8.8 \\
\hline & $+150 \%(3)$ & 5.5 & 6.2 & 6.8 & 7.7 & 8.3 & 9.2 \\
\hline & 0 & 0.6 & 0.1 & 0.4 & 1.2 & 1.7 & 2.5 \\
\hline
\end{tabular}

Table 5 shows the axial deflections of the upper support for GR3. The values shown in Table 5 correspond to the shear displacement of $+150 \%$ during the first and the second cycles, as well as at the end of the analyses. The lowest and highest axial deflections of the upper support are 0.1 and $13 \mathrm{~mm}$, respectively. For model B4, it is observed in Table 5 that when $10 \mathrm{MPa}$ of compression is applied, there are permanent deflections of $12 \%$ at the 

of the upper anchor plates for GR2, when the GR3 boundary conditions are applied, the thicker the steel shims the smaller the axial deflections that are experienced by the upper support. This is attributed to the fact that the boundary conditions of the upper support limited the yielding of the steel shims.

521 Similarly, to the GR2 case, there is an increase of the axial deflections of the upper support for GR3 when the values during the first and the second cycles of loading (at the shear displacement of $+150 \%$ ) are compared. This is a scenario that may cause failure of the bearing due to rubber cavitation, but this type of damage is beyond the scope of this study. It is also noticed that the thicker the steel shims, the smaller the axial deflections of the upper support under the same axial loads. This is attributed to the fact that the thicker steel shims remain elastic under higher compressive loads compared to the models with thinner steel shims. Comparing $\mathrm{B}_{1}$ with $\mathrm{B}_{6}$ under $10 \mathrm{MPa}$ of axial compression, at the target shear displacement, there is a decrease of the axial deflections of the upper support of $8 \%$ during the first and the second cycles of loading.

A comparison between the different boundary conditions of the upper support with regards to its effect on the axial deflections of the upper anchor plate is discussed here. The free upper support results in higher axial deflections when the imposed axial compressive load is large, i.e. $7 \mathrm{MPa}$ and $10 \mathrm{MPa}$. The deflections at the target shear displacement of the first cycle of loading (Fig. 4, point 1) are compared. The largest increase in axial deflections when GR2 and GR3 are compared is noticed when the $\mathrm{B}_{1}$ models are subjected to $10 \mathrm{MPa}$ of axial compression.

Table 5. Axial deflections of the right corner of the upper anchor plate during subsequent cycles of loadingunloading for GR3.

\begin{tabular}{|c|c|c|c|c|c|c|c|}
\hline \multicolumn{2}{|c|}{$\begin{array}{l}\text { average vertical stress } \\
(\mathrm{MPa})\end{array}$} & \multirow{3}{*}{$\begin{array}{c}-2 \mathrm{MPa} \\
1.5\end{array}$} & \multirow[t]{2}{*}{$0 \mathrm{MPa}$} & \multirow{2}{*}{$2 \mathrm{MPa}$} & \multirow{2}{*}{$5 \mathrm{MPa}$} & \multirow{2}{*}{$7 \mathrm{MPa}$} & \multirow{2}{*}{$10 \mathrm{MPa}$} \\
\hline & & & & & & & \\
\hline \multirow{3}{*}{$\begin{array}{l}\text { shear } \\
\text { strain }\end{array}$} & $+150 \%(1)$ & & 1.5 & 4.1 & 7.6 & 9.8 & 13.0 \\
\hline & $+150 \%$ (3) & 1.7 & 1.5 & 4.3 & 8.2 & 10.0 & 13.0 \\
\hline & 0 & 0.4 & 0.1 & 0.2 & 0.6 & 1.0 & 1.7 \\
\hline \multicolumn{8}{|c|}{$\mathrm{B}_{2}$} \\
\hline \multirow{3}{*}{$\begin{array}{l}\text { shear } \\
\text { strain }\end{array}$} & $+150 \%$ (1) & 1.4 & 1.5 & 4.1 & 7.6 & 9.8 & 12.0 \\
\hline & $+150 \%$ (3) & 1.6 & 1.5 & 4.3 & 8.2 & 10.0 & 13.0 \\
\hline & 0 & 0.4 & 0.1 & 0.2 & 0.6 & 1.0 & 1.6 \\
\hline \multicolumn{8}{|c|}{$\mathrm{B}_{4}$} \\
\hline \multirow{3}{*}{$\begin{array}{l}\text { shear } \\
\text { strain }\end{array}$} & $+150 \%$ & 1.2 & 1.6 & 4 & 7.4 & 9.5 & 12.0 \\
\hline & $+150 \%$ (3) & 1.4 & 1.6 & 4.2 & 7.9 & 10.0 & 13.0 \\
\hline & 0 & 0.3 & 0.1 & 0.2 & 0.7 & 1.0 & 1.6 \\
\hline \multicolumn{8}{|c|}{$\mathrm{B}_{6}$} \\
\hline shear & $+150 \%$ (1) & 1.1 & 1.6 & 3.9 & 7.1 & 9.1 & 12.0 \\
\hline strain & $+150 \%$ (3) & 1.3 & 1.6 & 4.1 & 7.5 & 9.8 & 12.0 \\
\hline
\end{tabular}




\subsection{Influence of the stiffness and the damping ratio due to the bearing rotation}

540

Table 6 shows the effective stiffness and damping ratio of model $\mathrm{B}_{4}$ under the different load combinations of shear displacement, rotation and axial loads. The three different upper support boundary conditions groups (GR1, GR2, GR3) are considered. The damping ratio is calculated as per Eq. (4). Figure 11 illustrates the shear stress-strain curves of model $\mathrm{B}_{4}$ for the three different groups of the upper support boundary conditions (GR1, GR2, GR3). It can be seen in Fig. 11 that for small values of average vertical stress (2 MPa tension, $0 \mathrm{MPa}$, and $2 \mathrm{MPa}$ compression) the different upper support boundary conditions have negligible influence on the isolator lateral behaviour. More specifically, the biggest difference regarding the stiffness is observed when $2 \mathrm{MPa}$ of compression is applied to the isolator and the upper support boundary conditions change from GR1 to GR2. There is a decrease in the stiffness of $6 \%$. On the other hand, when the axial compression is increased (i.e. $5 \mathrm{MPa}, 7$ $\mathrm{MPa}$ and $10 \mathrm{MPa}$ ), the influence of the support boundary conditions to the stiffness of the isolator is more evident. It can be seen in Fig. 11 that the freer the upper support to translate and rotate, the smaller the stiffness of the isolator. The largest decrease of the stiffness is $35 \%$ and is observed when the upper support boundary conditions change from GR1 to GR3, under 10 MPa of axial compression. This observation is in line with the observations by Kalfas et al. (2017b). The higher stiffness of the bearing when the upper support is restrained is considered reasonable since the additional restraints increase the stiffness of the isolators.

Regarding the influence of the upper support boundary conditions on the damping ratio of the isolators, it can be seen in Fig. 11 that when small values of axial loads (2 MPa tension, $0 \mathrm{MPa}$, and $2 \mathrm{MPa}$ compression) are applied to the isolator, there is a negligible difference of the damping ratio between the different upper support boundary conditions. The biggest damping ratio increase, when the axial load is small, is less than $1 \%$ and it occurs when the upper support boundary conditions change from GR2 to GR3, under $2 \mathrm{MPa}$ of axial compression. On the other hand, when the applied axial load is higher (5 MPa, $7 \mathrm{MPa}$ and $10 \mathrm{MPa}$ of compression) the damping ratio increases significantly, and this increase varies from $5 \%$, when the upper support boundary conditions change from fixed to partially restraint (from GR1 to GR2), under $5 \mathrm{MPa}$ of axial compression, to $57 \%$, when the boundary conditions of the upper support change from fixed to free movement (from GR1 to GR3), under $10 \mathrm{MPa}$ of axial compression. As such, fixed conditions of the upper support will lead to smaller values of damping ratio, which is in line with previous studies (Kalfas et al. 2017b). However, it should be noted at this point that the increase in damping as the rotational fixity of the top support is relaxed is not related to additional energy 
dissipated per cycle (refer to the hysteresis loops shown in Figure 11 which have approximately the same enclosed area) but rather to the aforementioned decrease in effective stiffness, which in turn results in an increase in effective damping ratio, based on Eq. (4).

Table 6. Effective stiffness and damping ratio, of model $\mathrm{B}_{4}$ under combined loading for the three different groups of upper support boundary conditions (GR1, GR2, GR3).

\begin{tabular}{cccccccc}
\hline \hline \multicolumn{2}{c}{ load $(\mathrm{MPa})$} & $-2 \mathrm{MPa}$ & $0 \mathrm{MPa}$ & $2 \mathrm{MPa}$ & $5 \mathrm{MPa}$ & $7 \mathrm{MPa}$ & $10 \mathrm{MPa}$ \\
\hline \multirow{2}{*}{$\mathrm{GR} 1$} & $\mathrm{~K}_{\text {eff }}(\mathrm{kN} / \mathrm{m})$ & 1212 & 1220 & 1217 & 1204 & 1194 & 1177 \\
& $\xi_{\text {eff }}(\%)$ & 11.9 & 11.8 & 12.1 & 12.6 & 12.8 & 12.8 \\
\hline \multirow{2}{*}{$\mathrm{GR} 2$} & $\mathrm{~K}_{\text {eff }}(\mathrm{kN} / \mathrm{m})$ & 1202 & 1178 & 1144 & 1082 & 1035 & 957 \\
& $\xi_{\text {eff }}(\%)$ & 11.5 & 11.8 & 12.3 & 13.2 & 13.9 & 14.9 \\
\hline \multirow{2}{*}{ GR3 } & $\mathrm{K}_{\text {eff }}(\mathrm{kN} / \mathrm{m})$ & 1208 & 1215 & 1183 & 1071 & 957 & 761 \\
& $\xi_{\text {eff }}(\%)$ & 12 & 11.8 & 12.3 & 14.0 & 15.9 & 20.1 \\
\hline \hline
\end{tabular}
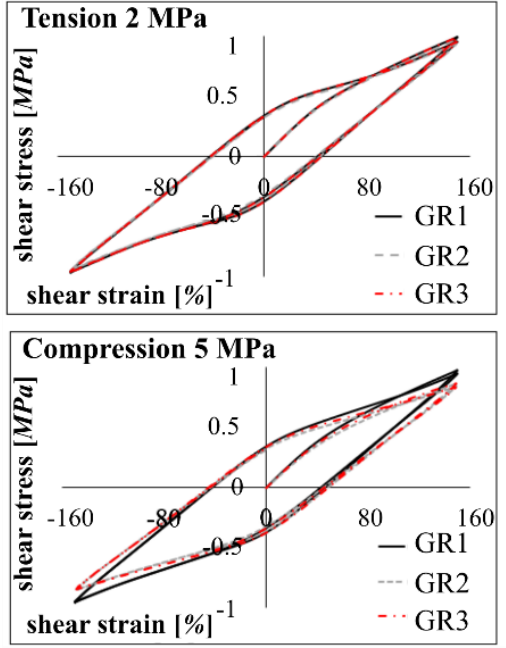
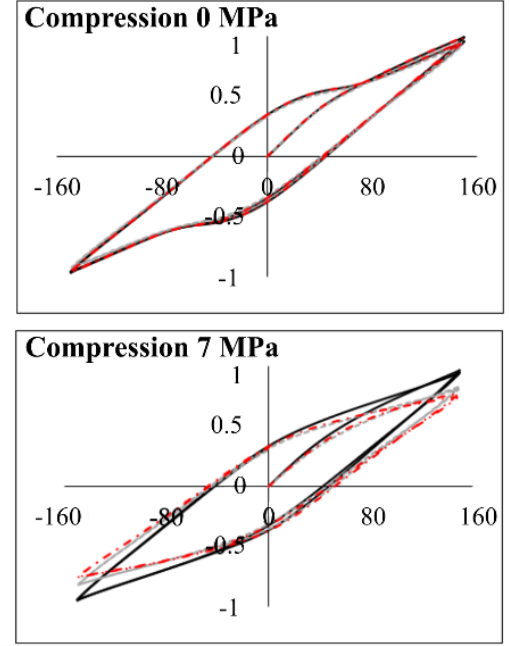
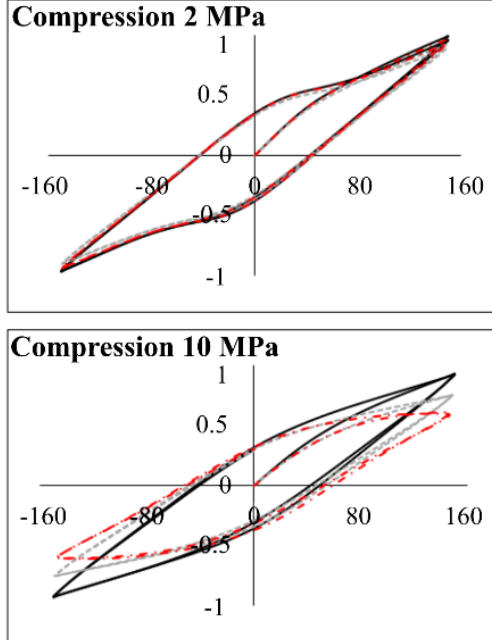

Fig. 11. Response of the elastomeric bearings with $4 \mathrm{~mm}$ steel shim thickness $\left(\mathrm{B}_{4}\right)$ under the combination of shear displacements and axial loads and different groups of the upper support boundary conditions (GR1, GR2, GR3).

\section{CONCLUSIONS}

Seismic isolation steel-reinforced elastomeric bearings are critical components of an isolated structure and as such are expected to experience little to no damage under design-earthquake excitations. Damage in the isolators due to yielding of the reinforcing steel shims could result in significant consequences on the superstructure. This paper investigated the effect of the steel reinforcement on the performance of low-damping elastomeric isolators. Of primary focus was the potential for damage due to yielding of the steel shims in the isolator and how this is 
affected by various factors, including steel shim thickness, average vertical stress, and the rotational restraint of the top support.

Realistic loading scenarios (based on real bridge analyses) imposed on the bearings to investigate the response of the bearings (e.g. damage, stiffness, damping etc). The study investigated the influence of the rotation of the upper anchor plate on the axial deflection of the upper support and the response of the steel shims, as well as on the stiffness and dissipation capacity of the isolators. The loads were a combination of shear displacement, rotation and axial loads, being either tensile (2 MPa) or compressive (0 MPa, $2 \mathrm{MPa}, 5 \mathrm{MPa}, 7 \mathrm{MPa}$ and $10 \mathrm{MPa}$ ). Four different composite steel-reinforced elastomeric bearings were modelled in the FE software ABAQUS/CAE, which was used for the numerical study. The following summarizes the most salient findings of the study:

1) Thicker steel shims are much less likely to yield under the design shear strains compared to thinner steel shims. The elastomeric bearings with 6-mm-thick steel shims exhibited less yielding under $10 \mathrm{MPa}$ of compression, whilst the bearings with 1-, 2-, and 4-mm-thick steel shims experienced more extensive yielding, which increased as the rotation boundary condition of the upper anchor plate was changed from fixed (GR1) to limited (GR2), to free (GR3).

2) The steel-reinforced elastomeric bearings with 6-mm-thick shims experience $16 \%$ smaller axial deflections compared to the ones with 1-mm-thick shims.

3) The vulnerability of the elastomeric bearings to damage is affected by the thickness of the steel shims. There is a decrease of more than $20 \%$ in vulnerability when the thickness of the steel shims is increased from $2 \mathrm{~mm}$ to $4 \mathrm{~mm}$ and from $4 \mathrm{~mm}$ to $6 \mathrm{~mm}$.

4) The axial deflections of the upper anchor plate that affects the lateral behaviour of the isolators, are significantly affected by the boundary conditions considered. The freer the upper support to rotate the larger the axial deflection that the upper support experiences. This is more evident for the case of $10 \mathrm{MPa}$ axial compression, where for $1 \mathrm{~mm}$ of steel shim thickness, the deflections increase by $46 \%$ from GR 2 to GR3.

5) The thickness of the steel shims does not affect the axial deflection of the upper bearing plate for the GR2 boundary conditions. On the other hand, in the case of GR3, the steel shim thickness affects the upper support axial deflections, and an increase from $1 \mathrm{~mm}$ to $6 \mathrm{~mm}$ leads up to $8 \%$ reduction in axial deflection.

6) The effective stiffness of the isolators decreases when the upper bearing plate boundary conditions change from GR1 to GR3. On the contrary, the damping ratio increases when the upper bearing plate boundary conditions change from GR1 to GR3. 
It is reminded that the isolators are expected to remain elastic or experience little damage under the design seismic actions. This study showed that the elastomeric bearings may experience damage under seismic actions. The increase of the thickness of the steel shims reduces the bearings vulnerabilities. The reduction of the weight of the bearings through the reduction of the thickness of the steel shims was also attempted by performing analyses with models that had steel shims with thickness below the provisions of the codes i.e. $1 \mathrm{~mm}$. It was observed that the thinner the steel shims the more extensive is their plasticity and consequently the damage of the bearings.

\section{REFERENCES}

American Association of State Highway and Transportation Officials, AASHTO (2014). "Guide Specifications for Seismic Isolation Design". $4^{\text {th }} E d$., Washington DC, USA.

Aria M, Akbari R. Inspection (2013). "Condition Evaluation and replacement of elastomeric bearings in road bridges." Structure and Infrastructure Engineering, 9(9), 918-934.

Bergström JS, Boyce MC (1998). "Constitutive modeling of the large strain time-dependent behavior of elastomers." Journal of Mechanics Physics Solids, 46(5), 931-954.

Bradley GL, Chang PC, Mckenna GB (2001). "Rubber modeling using uniaxial test data." Journal of Applied Polymer Science, 81.4, 837-848.

Camara A, Cristantielli R, Astiz MA, Málaga-Chuquitaype C (2017). "Design of hysteretic dampers with optimal ductility for the transverse seismic control of cable- stayed bridges." Earthquake Engineering \& Structural Dynamics, 46(11), 1811-1833.

Crowder AP, Becker TC (2017). "Experimental investigation of elastomeric isolation bearings with flexible supporting columns." Journal of Structural Engineering, 143(7), 04017057.

Dassault Systèmes (2014a). ABAQUS/CAE 6.13 user's Manual. Abaqus Ver. 6.13 Documentation: Providence, RI.

Dassault Systèmes (2014b). Computer Program ABAQUS/CAE. Providence, RI.

Diani J, Fayolle B, Gilormini P (2009). “A review on the Mullins effect.” European Polymer Journal, 45(3), 601612.

EN 1337-3: 2005 (2005). "Structural bearings - Part 3: Elastomeric Bearings." European Committee for Standardization, Brussels, Belgium. 
EN 1998-2 (2005). Eurocode 8: "Design of Structures for Earthquake Resistance, Part 2: Bridges.” European Committee for Standardization, Brussels, Belgium.

Faridmehr I, Osman MH, Adnan AB, Nejad AF, Hodjati R Azimi M (2014). "Correlation between engineering stress-strain and true stress-strain curve." American Journal of Civil Engineering and Architecture, 2(1), 53-59. Forcellini D, Mitoulis SA, Kalfas KN (2017). "Study on the response of elastomeric bearings with 3D numerical simulations and experimental validation." COMPDYN 2017; 6th International Conference on Computational Methods in Structural Dynamics and Earthquake Engineering, 15-17 June, Rhodes Island, Greece.

Han X, Warn GP (2015). "Mechanistic model for simulating critical behavior in elastomeric bearings." Journal of Structural Engineering, 141(5), 04014140.

Kalfas KN, Mitoulis SA (2017). "Performance of steel-laminated rubber bearings subjected to combinations of axial loads and shear strains." Procedia Engineering, 199, 2979-2984.

Kalfas KN, Mitoulis SA, Katakalos K (2017a). "Numerical study on bridge elastomeric bearings subjected to large shear strains with emphasis on local tension." $16^{\text {th }}$ World Conference on Earthquake Engineering, 9-13 January, Santiago, Chile.

Kalfas KN, Mitoulis SA, Katakalos K (2017b). "Numerical study on the response of steel-laminated elastomeric bearings subjected to variable axial loads and development of local tensile stresses." Engineering Structures, 134, 346-357.

Kawashima K, Kosa K, Takahashi Y, Akiyama M, Nishioka T, Watanabe G, Koga H, Matsuzaki H (2011). "Damage of bridges during 2011 Great East Japan Earthquake." Proceedings of 43rd Joint Meeting, US-Japan Panel on Wind and Seismic Effects, 29-30 August, Tsukuba Science City, Japan.

Kawashima K, Matsuzaki H (2012). "Damage of road bridges by 2011 Great East Japan (Tohoku) Earthquake.” 15th World Conference of Earthquake Engineering, 24-28 September, Lisbon, Portugal.

Kelly JM, Konstantinidis D (2009). "Steel shim stresses in multilayer bearings under compression and bending." Journal of Mechanics of Materials and Structures, 4(6), 1109-1125.

Kelly JM, Konstantinidis D (2011). Mechanics of Rubber Bearings for Seismic and Vibration Isolation. John Wiley \& Sons, New York, USA.

Kelly JM, Takhirov SM (2004). "Experimental study of steel reinforced rubber bearings with various shim thicknesses." Proc. SEM X International Congress and Exposition on Experimental and Applied Mechanics, 710 June, California, USA. 
Kumar M, Whittaker AS (2017). "Effect of seismic hazard definition on isolation-system displacements in nuclear power plants." Engineering Structures, 148, 424-435.

Kwon OS, Jeong SH (2013). "Seismic displacement demands on skewed bridge decks supported on elastomeric bearings." Journal of Earthquake Engineering, 17(7), 998-1022.

Maureira N, De la Llera J, Oyarzo C, Miranda S (2017). "A nonlinear model for multilayered rubber isolators based on a co-rotational formulation.” Engineering Structures, 131: 1-13.

Mitoulis SA (2015). "Uplift of elastomeric bearings in isolated bridges subjected to longitudinal seismic excitations." Structure and Infrastructure Engineering, 11(12), 1600-1615.

Mullins L (1969). "Softening of rubber by deformation." Rubber Chemistry and Technology, 42(1), 339-362.

Naeim F, Kelly JM (1999). Design of Seismic Isolated Structures-From Theory to Practice. John Wiley \& Sons, New York, USA.

Nagarajaiah S, Ferrell K (1999). "Stability of elastomeric seismic isolation bearings.” Journal of Structural Engineering, 125(9), 946-954.

Ogden WR (1972). "Large Deformation Isotropic Elasticity-On the Correlation of Theory and Experiment for Incompressible Rubberlike Solids." Proceedings of the Royal Society of London. Series A, Mathematical and Physical Sciences, 326(1567): 565-584.

Ohsaki M, Miyamura T, Kohiyama M, Yamashita T, Yamamoto M, Nakamura N (2015). "Finite-element analysis of laminated rubber bearing of building frame under seismic excitation." Earthquake Engineering \& Structural Dynamics, 44(11), 1881-1898.

Panetsos P (2016). "Inspection, assessment and maintenance of Greek concrete bridges bearings. Evaluation of the influence of various types of damage to the structural integrity of bridges." Panhellenic Concrete Conference, 11-12 November, Thessaloniki, Greece (in Greek).

Ragni L, Tubaldi E, Dall'Asta A, Muhr A (2018). "Biaxial shear behaviour of HDNR with Mullins effect and deformation-induced anisotropy.” Engineering Structures, 154, 78-92.

Rastgoo Moghadam S, Konstantinidis D (2017). "Finite element study of the effect of support rotation on the horizontal behavior of elastomeric bearings." Composite Structures, 163, 474-490.

Ravari AK, Othman IB, Ibrahim ZB, Ab-Malek K (2012). "P- $\Delta$ and end rotation effects on the influence of mechanical properties of elastomeric isolation bearings." Journal of Structural Engineering, 138(6), 669-675. 
Stanton JF, Roeder CW, Mackenzie-Helnwein P, White C, Kuester C, Craig B (2007). Rotation Limits for Elastomeric Bearings. National Cooperative Highway Research Program (NCHRP), Report 596, Washington DC, USA.

Takahashi Y (2012). "Damage of rubber bearings and dampers of bridges in 2011 Great East Japan earthquake." Proceedings of the International Symposium on Engineering Lessons Learned from the 2011 Great East Japan Earthquake, 1-4 March, Tokyo, Japan, 1333-1342.

Titirla M, Zarkadoulas N, Mitoulis SA, Mylonakis G (2017). "Rocking isolation of bridge piers using elastomeric pads." $16^{\text {th }}$ World Conference on Earthquake Engineering, 9-13 January, Santiago, Chile.

Tubaldi E, Mitoulis SA, Ahmadi H, Muhr A (2016). "A parametric study on the axial behaviour of elastomeric isolators in multi-span bridges subjected to horizontal excitations." Bulletin of Earthquake Engineering, 14(4), 1285-1310, DOI: 10.1007/s10518-016-9876-9.

Van Engelen NC, Kelly JM (2014). "Correcting for the influence of bulk compressibility on the design properties of elastomeric bearings." Journal of Engineering Mechanics, 141(6), 04014170.

Van Engelen NC, Konstantinidis D, Tait MJ (2017a). "Shear strain demands in elastomeric bearings subjected to rotation.” Journal of Engineering Mechanics, 143(4), 04017005.

Van Engelen NC, Konstantinidis D, Tait MJ (2017b). "Simplified approximations for critical design parameters of rectangular fiber-reinforced elastomeric isolators." Journal of Engineering Mechanics, 143(8), 06017009.

Van Engelen NC, Tait MJ, Konstantinidis D (2016). "Development of design code oriented formulas for elastomeric bearings including bulk compressibility and reinforcement extensibility." Journal of Engineering Mechanics, 142(6), 04016024.

Weisman J, Warn GP (2012). "Stability of elastomeric and lead-rubber seismic isolation bearings." Journal of Structural Engineering, 138(2), 215-223.

Xiang N, Li J (2017). "Experimental and numerical study on seismic sliding mechanism of laminated-rubber bearings.” Engineering Structures, 141, 159-174. 